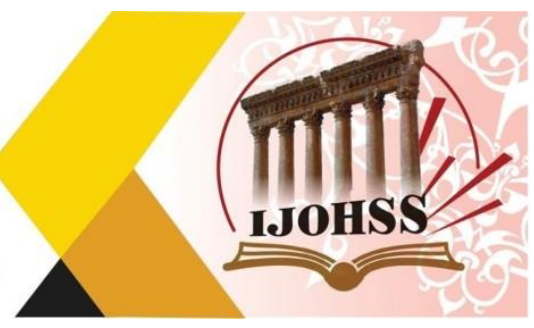

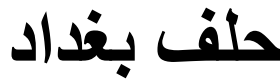 \\ (دراسة تاريخية سياسية معاصرة للمدة من 1955- 1959)
}

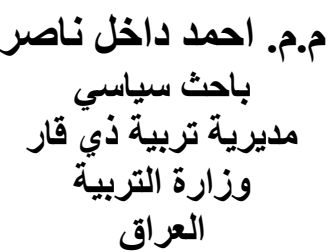

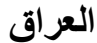

\author{
م.م. خالا عبد الرحمن جبر

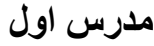 \\ مديرية تربية ذي قار

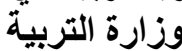 \\ العراق
}

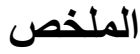

تعد الحرب العالمية الثانية نقطة تحول كبرى في تاريخ العلاقات الدولية، إذ أظهرت بروز قوى جديدة عظمى

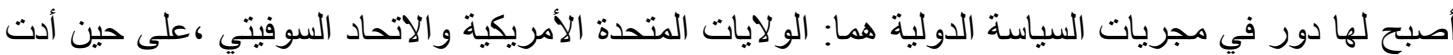
هذه الحرب إلى تراجع الدور البريطاني عما كان عليه في السابق على صعد مختلفة في العلاقات الدولية بخاصة في منطقة الثرق الأوسط. وهو ما حفز الولايات المتحدة إلى اخذ الدور البريطاني السابق في المنطقة. وبما أن الاتحاد السوفيتي يحظى بمكانة جيو سياسية وجيو اقتصادية بالنسبة للشرق الأوسط خصوصا، وان سياستها بدت بعد الحرب العالمية الثانية أكثر تعاطفا مع شعوب المنطقة، وأخذت تقدم الدعم لحركات التحرير في الكثير من دول العالم الثالث، لاسيما وان العديد من هذه الدول الحديثة الاستقلال أخذت تتأثر بطابع نمط التنمية الماركسي الذي حقق نجاحات اقتصادية في تلك المدة، فما بوسع الولايات المتحدة الأمريكية إلا أن تقوم بخطوة إستباقية مفادها تطويق الاتحاد السوفيتي، و إيقاف المد الثنيو عي للمنطقة لا سيما و إنها أصبحت بعد الحرب العالمية الثانية القوى العظمى من دون شك .

الكلمات المفتاحية: حلف بغداد، تاريخ العراق المعاصر. 


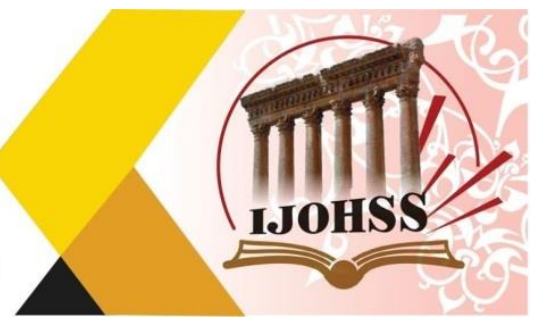

\title{
Baghdad's Violent
}

\section{(A political contemporary study" for the period of 1955-1959)}

\author{
Assist.Lect. Khaled Abdul Rahman Jabr \\ First teacher \\ Dhi Qar Education Directorate \\ Ministry of Education \\ Iraq
}

\author{
Assist.Lect. Ahmed Dakhil Nasser \\ Political researcher \\ Dhi Qar Education Directorate \\ Ministry of Education \\ Iraq
}

\begin{abstract}
The Second World War is a major turning point in the history of international relations, as it showed the emergence of new great powers that have played a role in the course of international politics, namely: the United States of America and the Soviet Union, while this war led to a decline in the British role from what it was in the past at various levels In international relations, especially in the Middle East. This prompted the United States to take the previous British role in the region. And since the Soviet Union enjoys a geo-political and geopolitical status with regard to the Middle East in particular, and that its policy appeared after World War II more sympathetic to the peoples of the region, and began to provide support to the liberation movements in many countries of the third world, especially since many of these newly independent countries began to be affected. With the character of the Marxist development pattern that achieved economic success during that period, the United States of America can only take a preemptive step to encircle the Soviet Union and stop the communist tide of the region, especially since it became after the Second World War the great powers without the help.
\end{abstract}

Keywords: The Baghdad Pact, Contemporary Iraq History. 


\section{اللمجلة اللحولية اللفلوم الآسانية والإمتماعية}

International Journal of Humanities and Social Sciences website:www.ijohss.com Email:editor@ijohss.com ISSN: $2415-4822$

العدد (15) Volume (15) September 2020

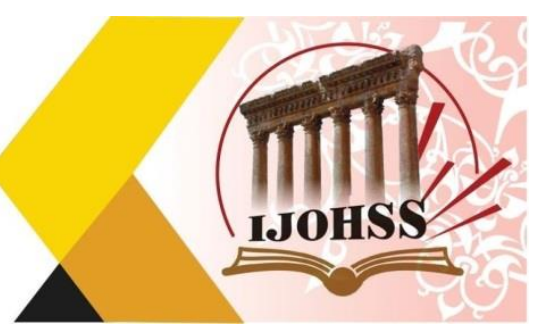

المقدمة

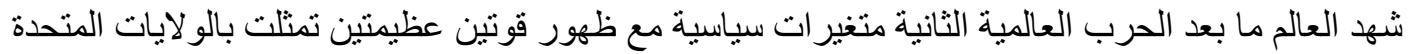

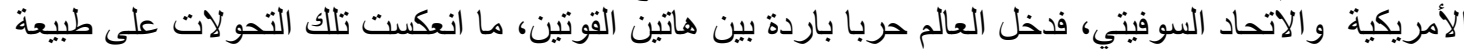

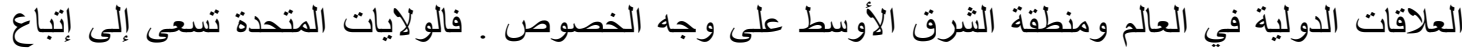

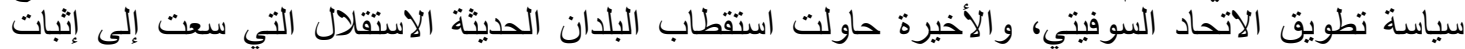

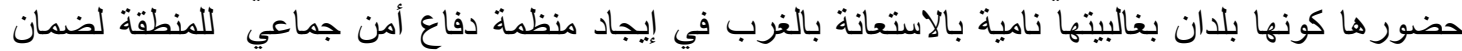
استقر ار ها .

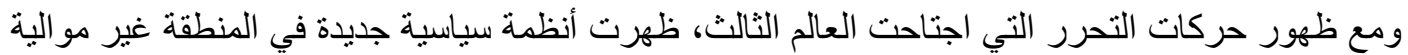

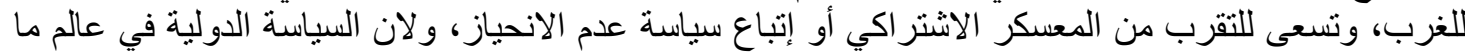

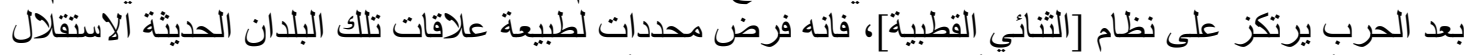

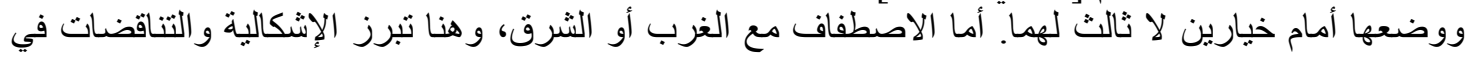

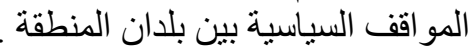

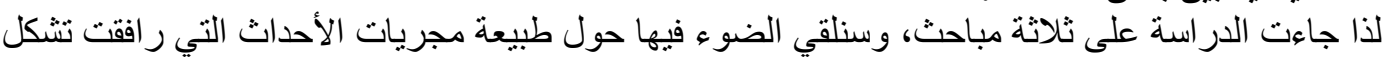

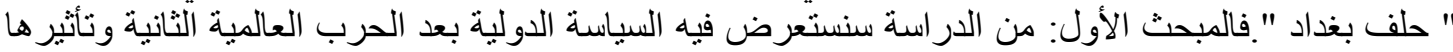

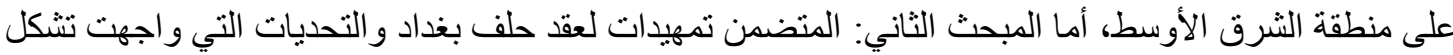
الحف في الداخل و الخارج، ور هانات حكومة السعيد. وفي المبحث الثالث: سندرس المتغير الثيرات السياسية في منطقة الشرق الأوسط، و انعكاساتها على الحلف.

\section{المبحث الأول}

\section{السياسة الدولية بعد الحرب العالمية الثانية وتثأثيرها على منطقة الثرق الأوسط}

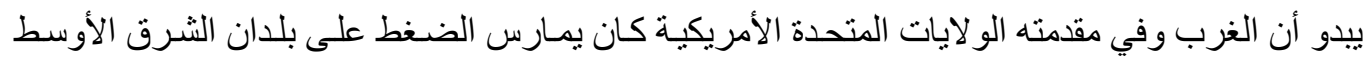

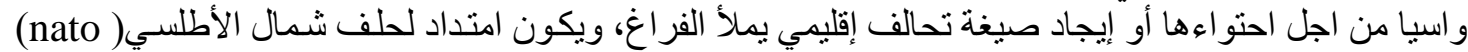

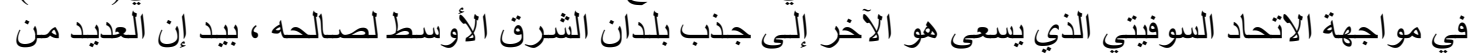

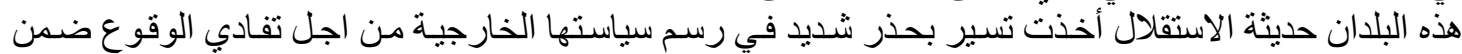

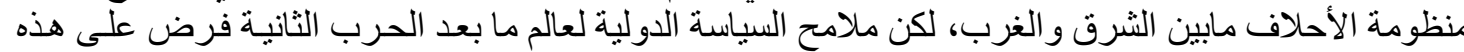

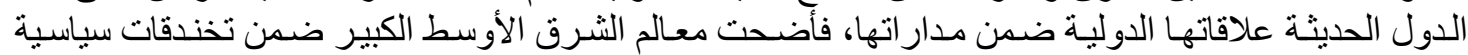

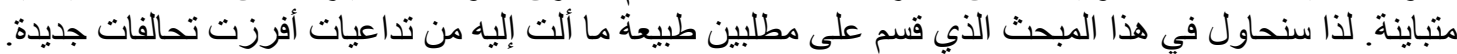

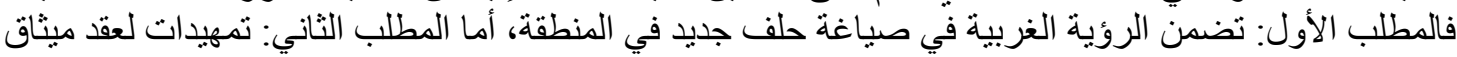

بغداد.

أولا : الروئة الغربية في صياغة حلف جديد في المنطقة

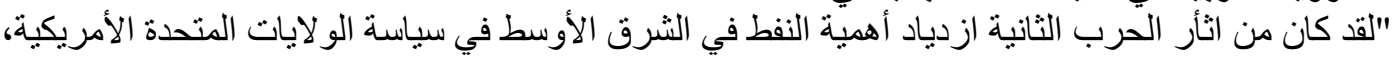

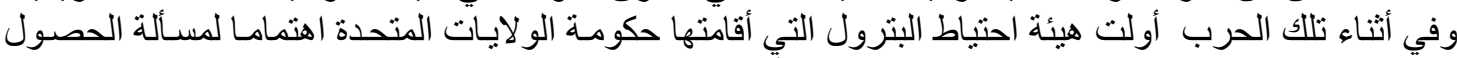

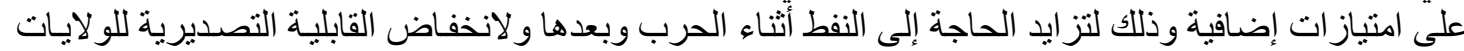

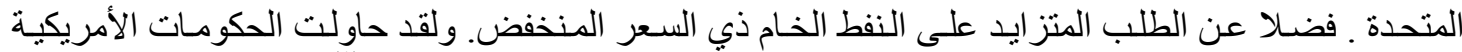

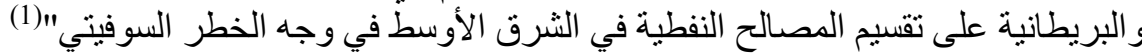

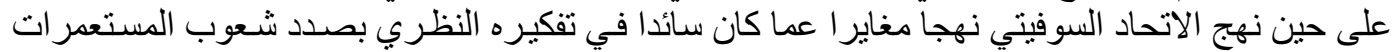

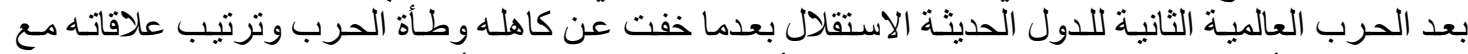

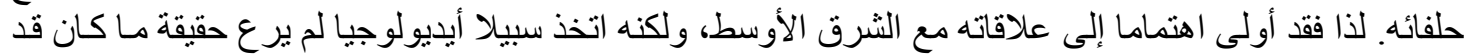

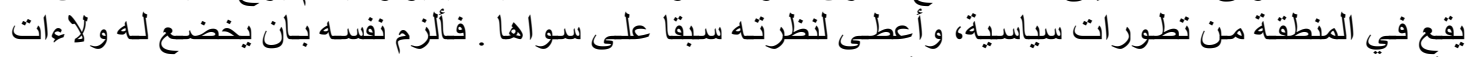

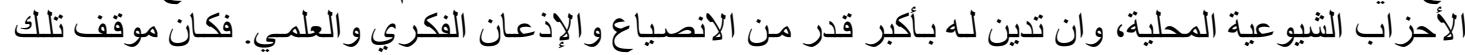


International Journal of Humanities and Social Sciences

website:www.ijohss.com

Email:editor@ijohss.com

ISSN: $2415-4822$

2020 لسبتهبر

العدد (15)

Volume (15)

September 2020

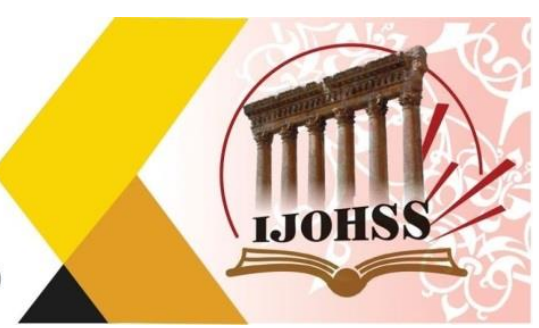

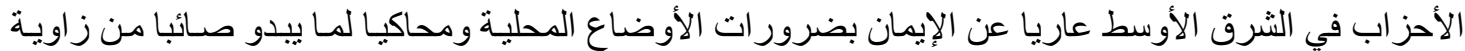

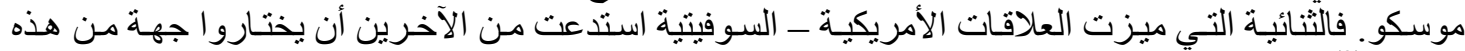

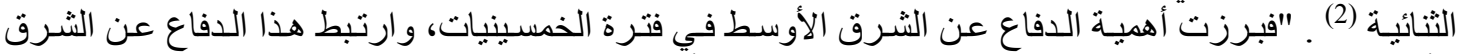

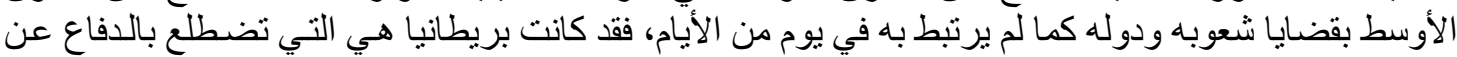

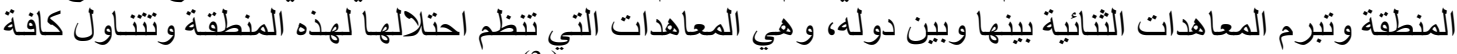

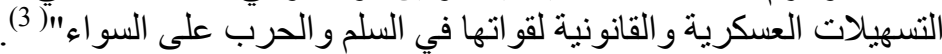

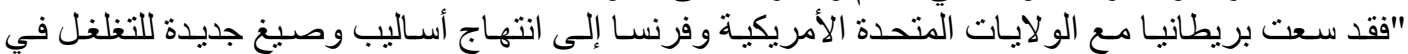

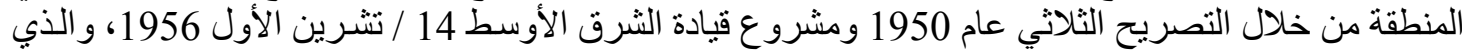

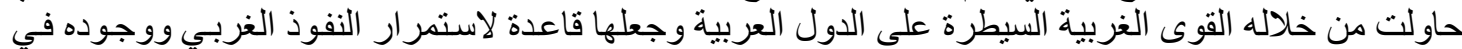

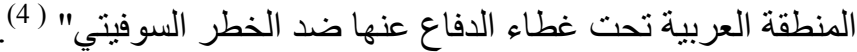

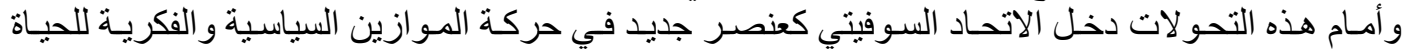

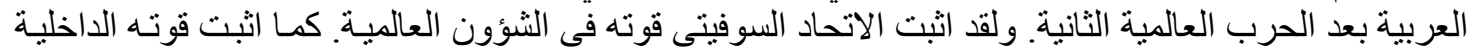

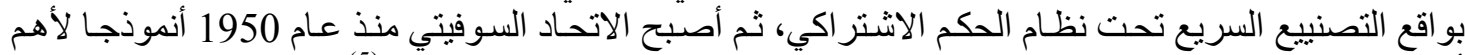

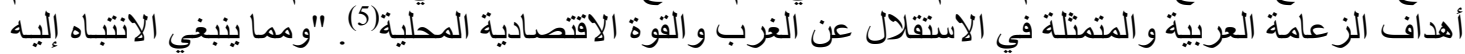

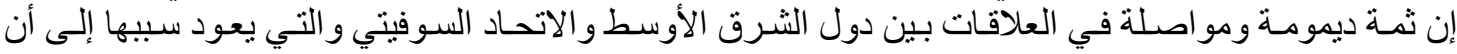

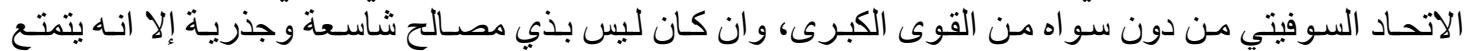

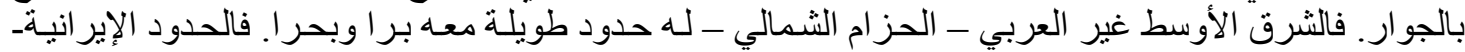

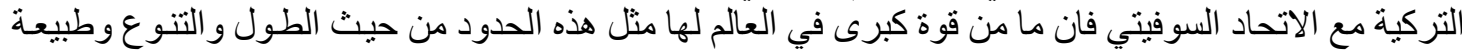

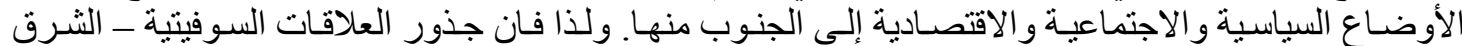

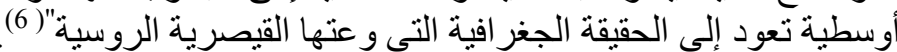

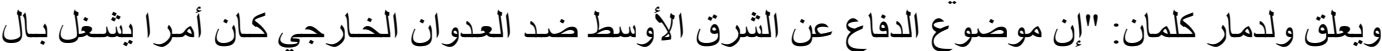

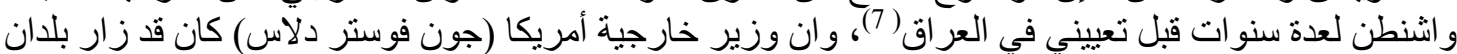

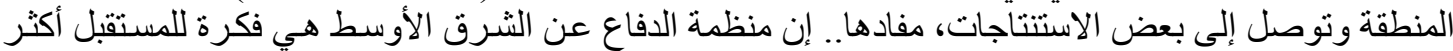

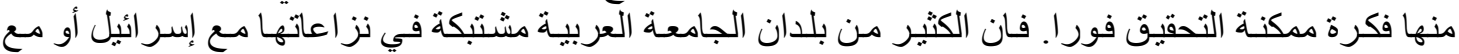

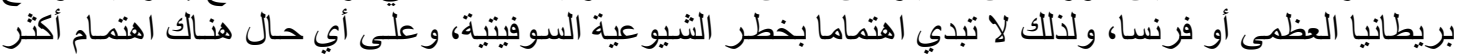

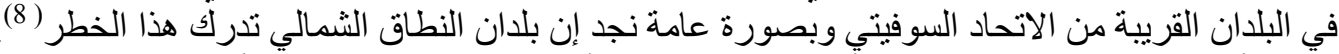

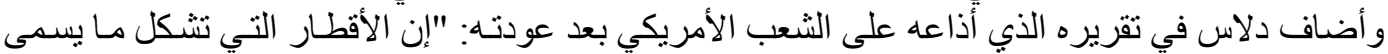

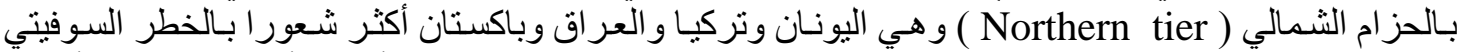

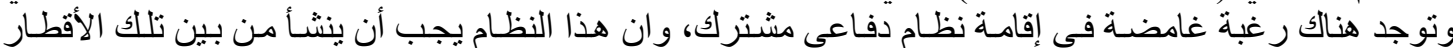

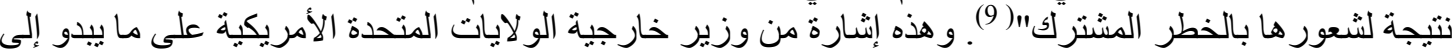

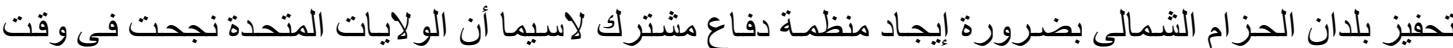

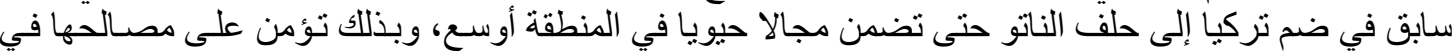
منطقة الثرق الأوسط.

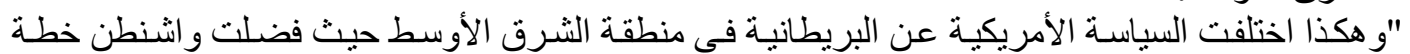

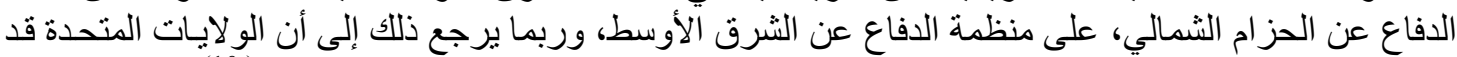

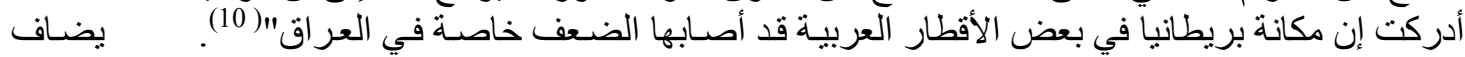

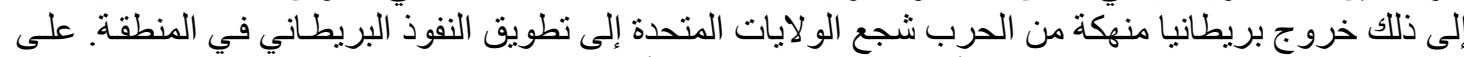

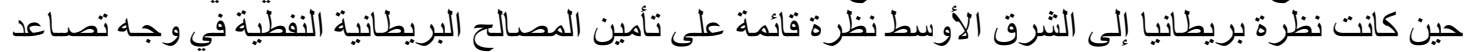

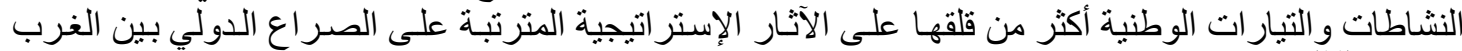

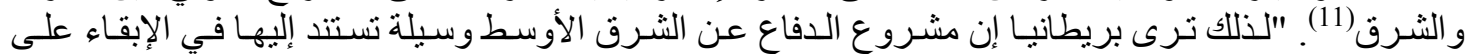


International Journal of Humanities and Social Sciences

website:www.ijohss.com

Email:editor@ijohss.com

ISSN: $2415-4822$

2020 لسبتمبر

(15) العدد (15)

Volume (15) September 2020

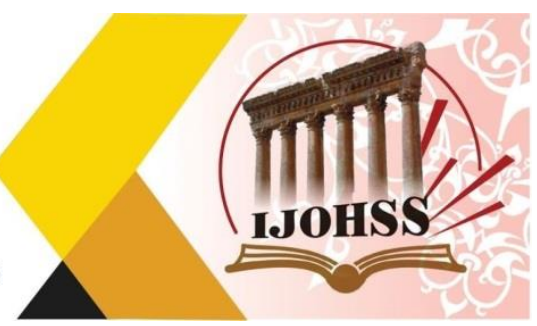

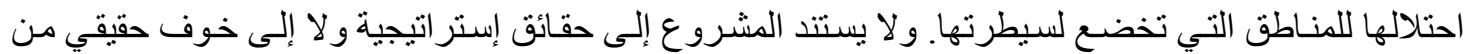

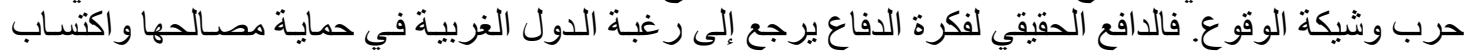

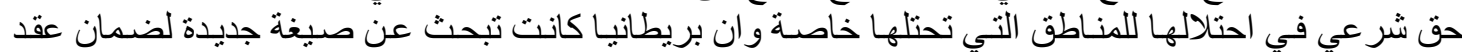

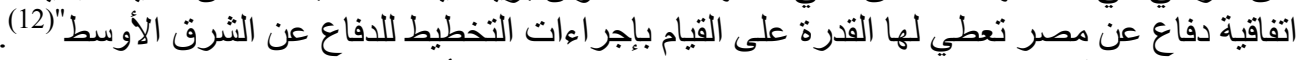

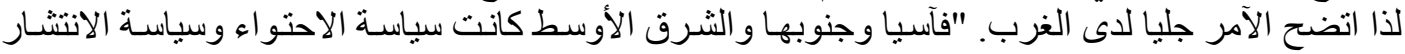

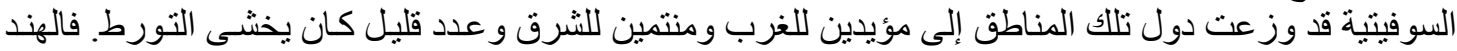

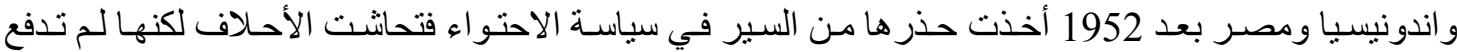

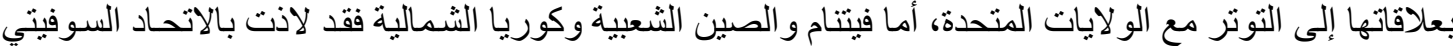

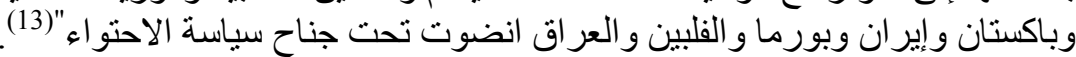

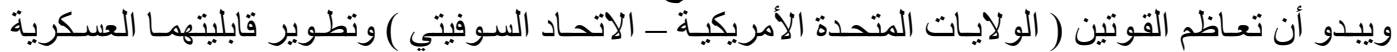

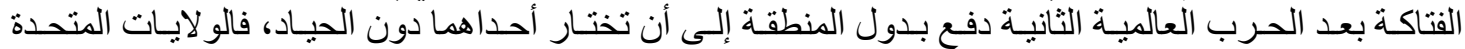

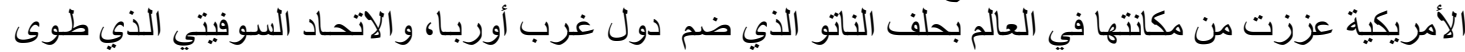

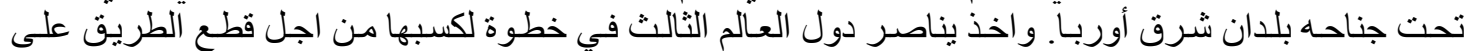

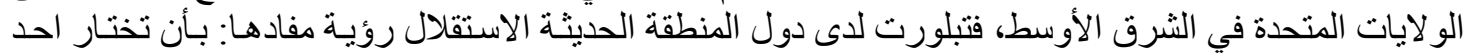

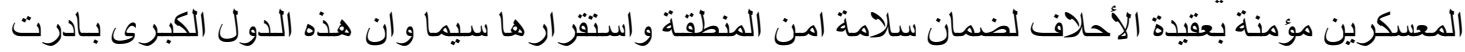

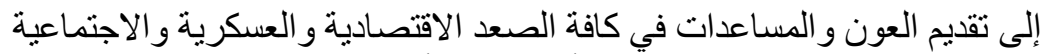

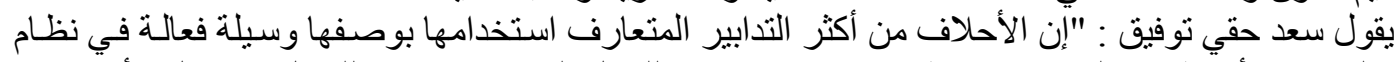

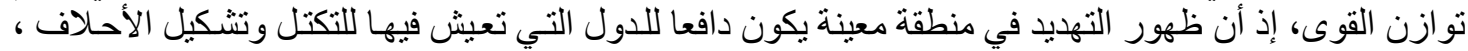

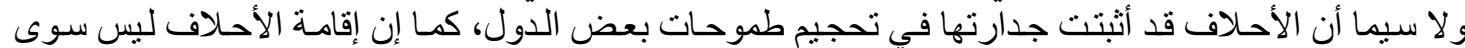

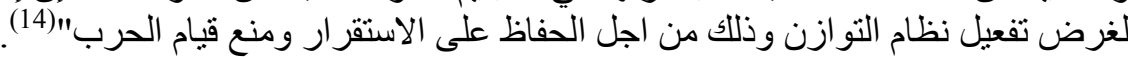

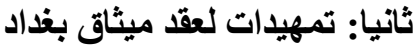

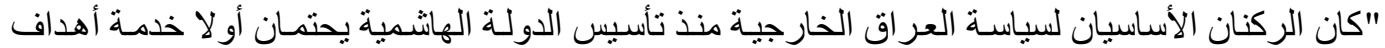

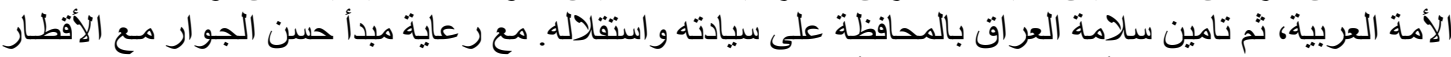

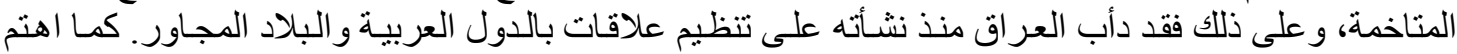

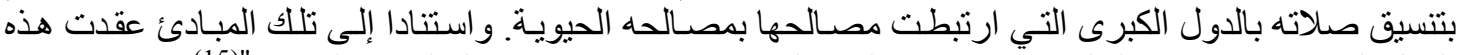

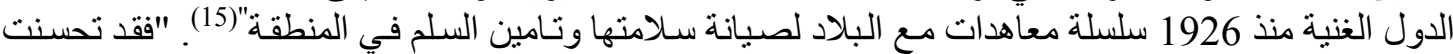

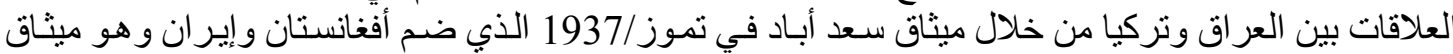

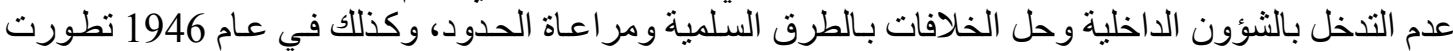

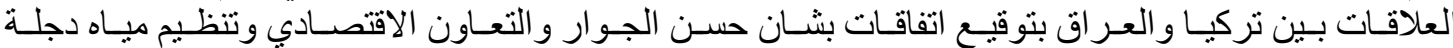

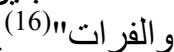

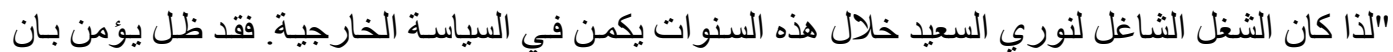

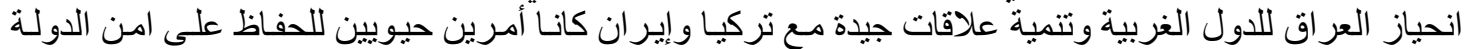

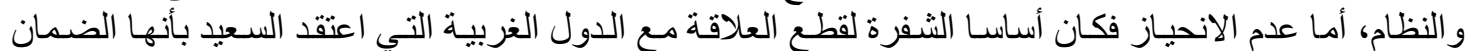

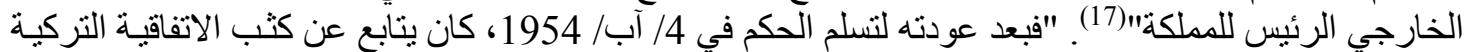

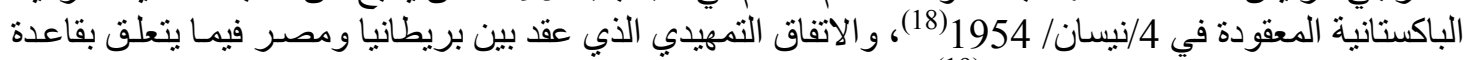

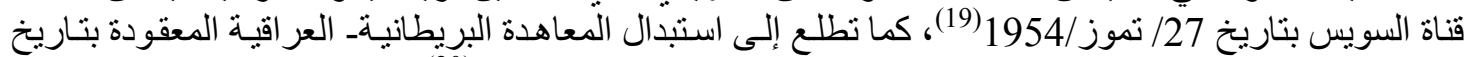

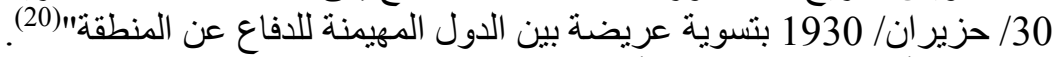

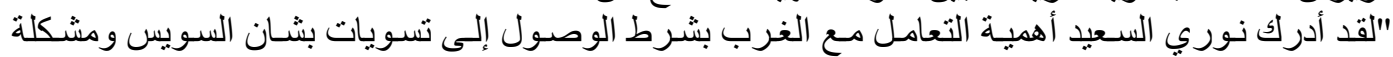

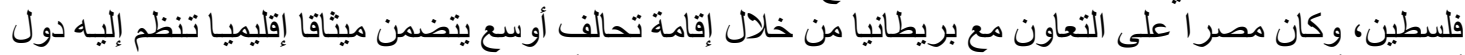

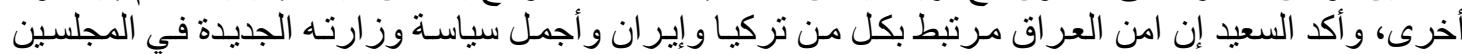

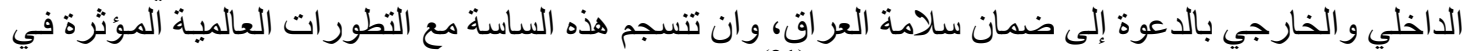

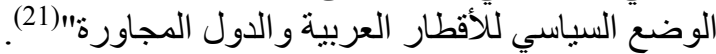


International Journal of Humanities and Social Sciences

website:www.ijohss.com

Email:editor@ijohss.com

ISSN: $2415-4822$

2020 لسبتمبر

العدد (15)

Volume (15) September 2020

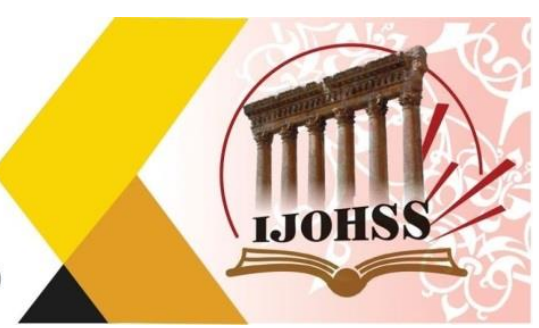

ييدو أن استثر افات جديدة طر أت في ذهن الساسة العر اقيين في تلك المرحلة من تاريخ العر اق السياسي حيال

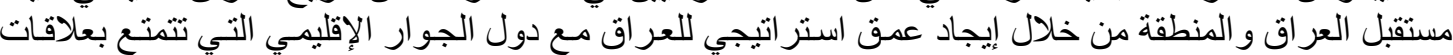

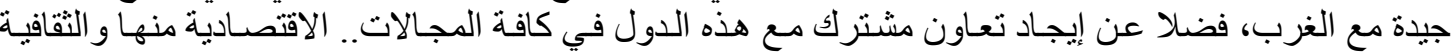

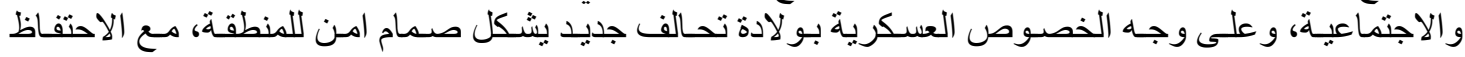

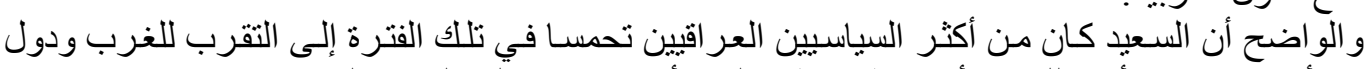

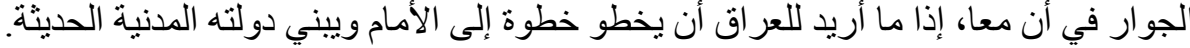

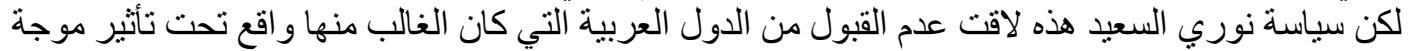

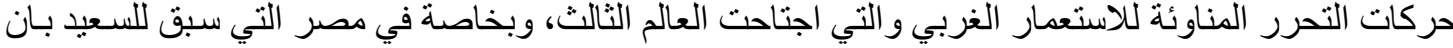

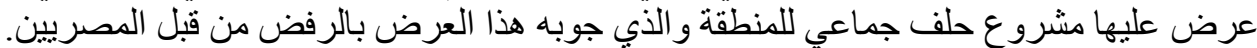

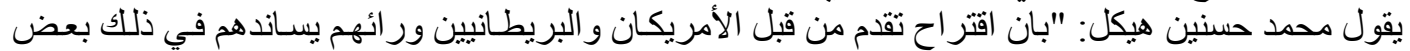

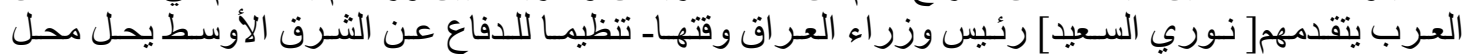

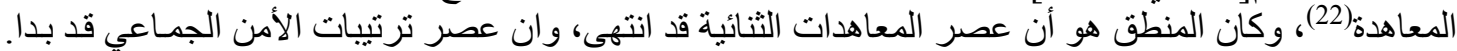

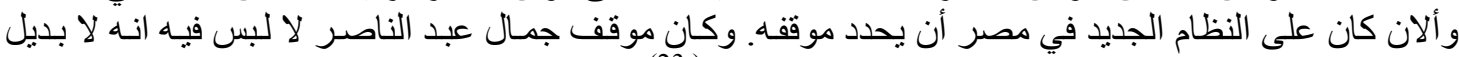

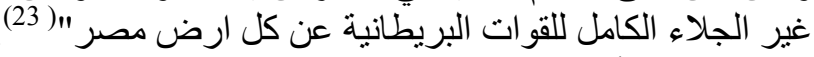

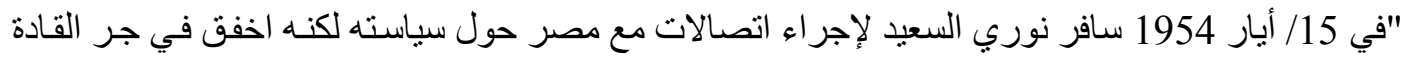

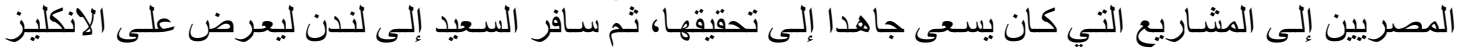

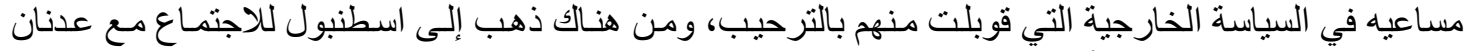

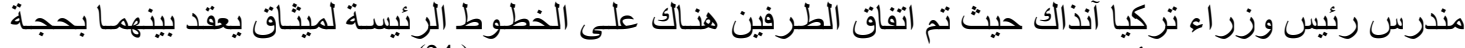

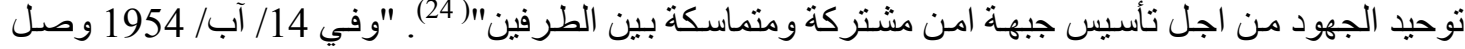

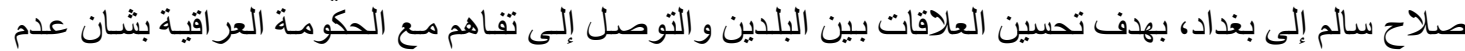

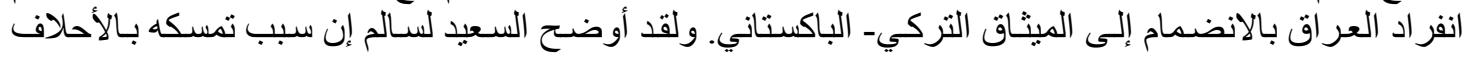

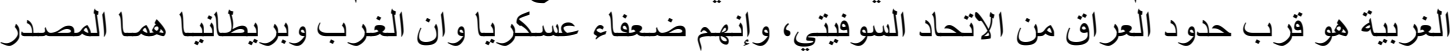

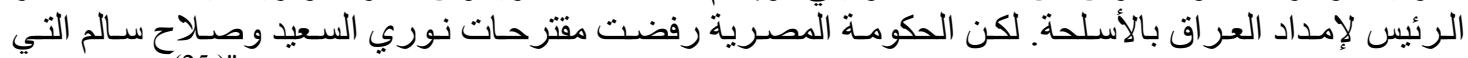

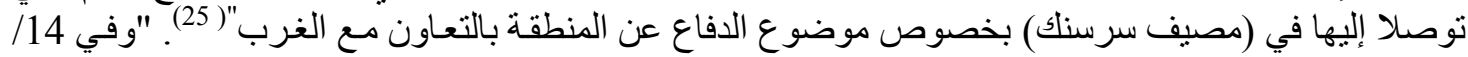

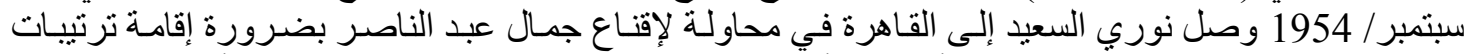

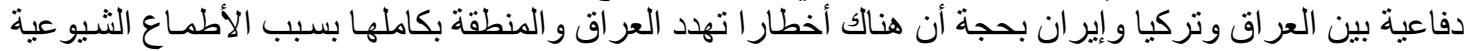

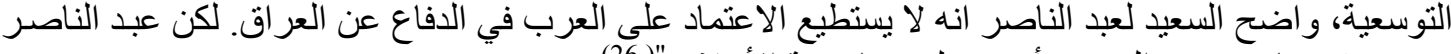

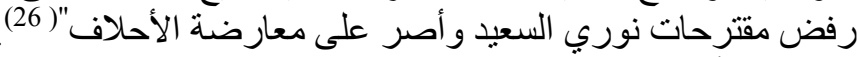

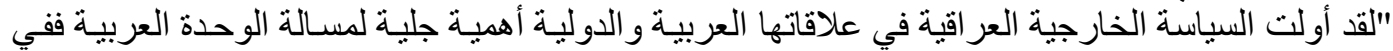

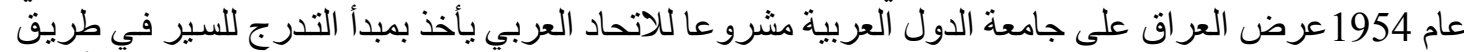

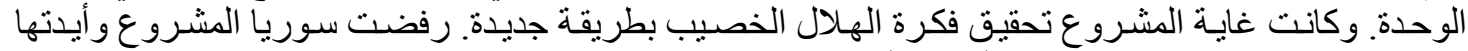

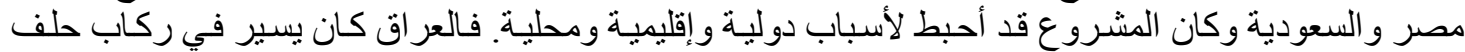

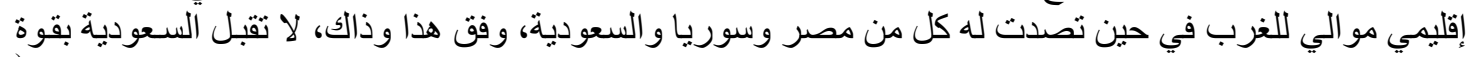

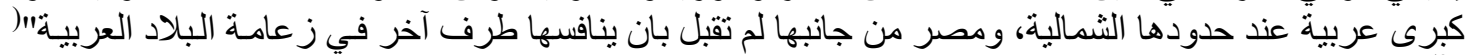

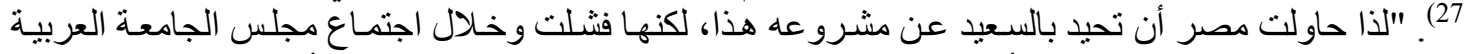

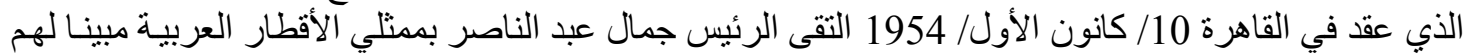

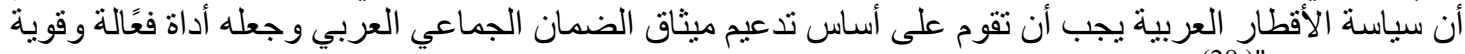

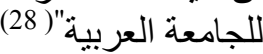


International Journal of Humanities and Social Sciences

website:www.ijohss.com

Email:editor@ijohss.com

ISSN: $2415-4822$

العدد (15) ل 2020

Volume (15) September 2020

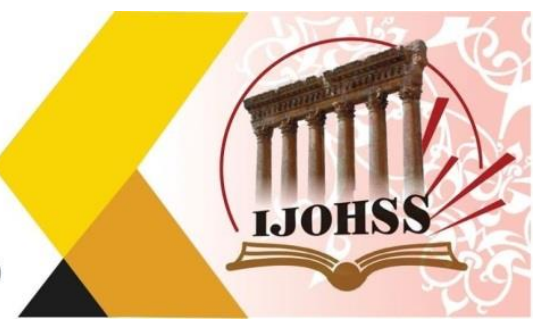

حلف بغداد بين تحديات الداخل والخارج الثاني ورهانات حكومة السعيد

أدرك نوري السعيد إن معالم الرؤية اتضحت، وان من مصلحة العر اق في الوقت الر اهن هو : أن يقوم بالمهــة

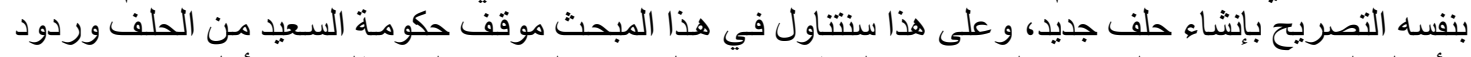

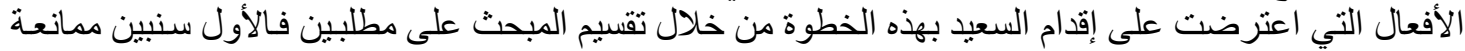

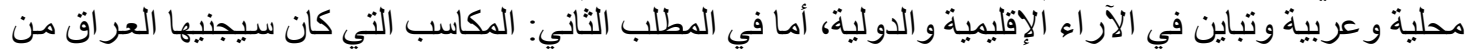

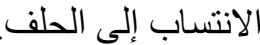

أولا : ممانعة محلية وعربية وتباين في الآراء الإقليمية والدولية

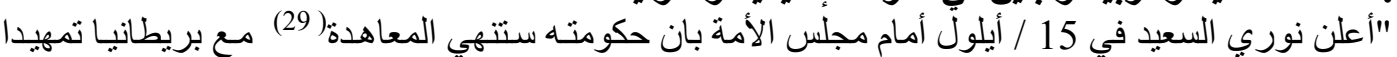

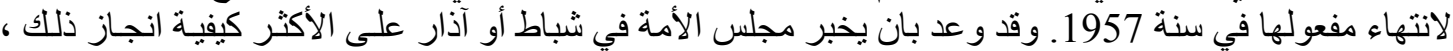

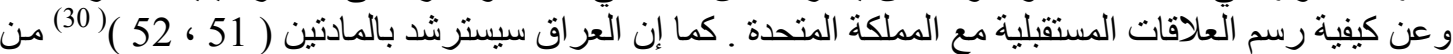

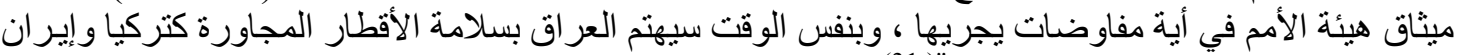

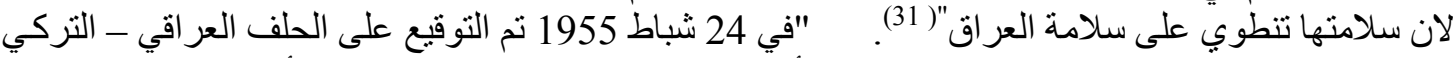

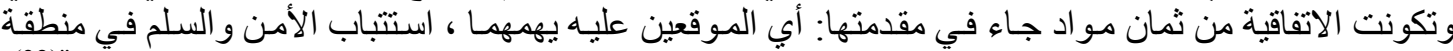

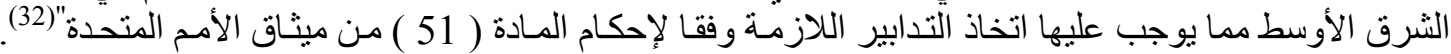

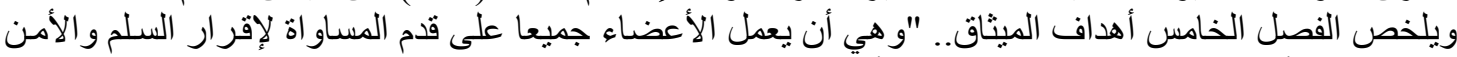

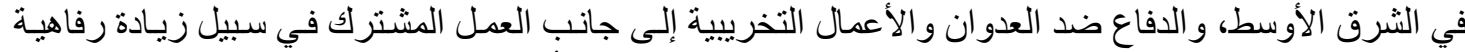

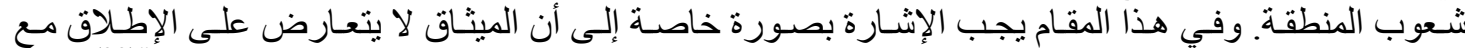

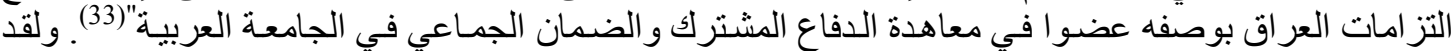

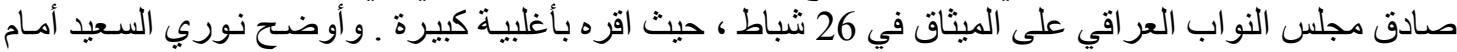

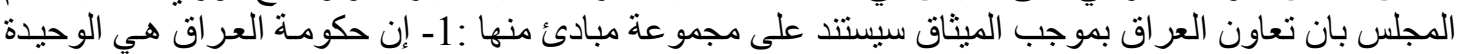

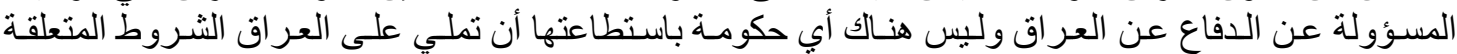

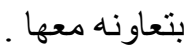

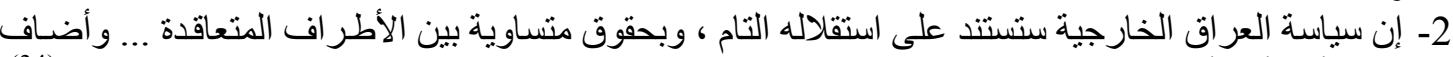

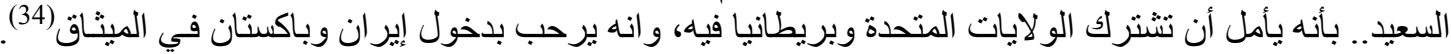

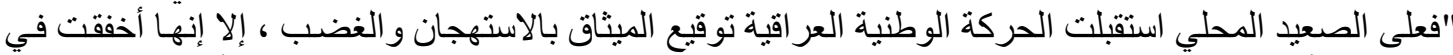

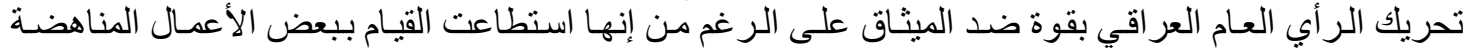

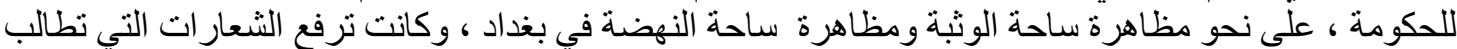

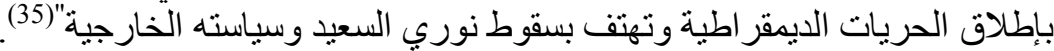

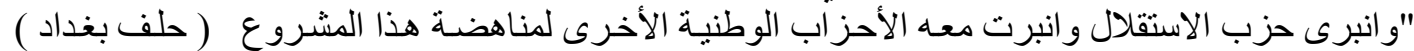

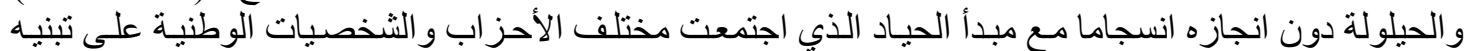

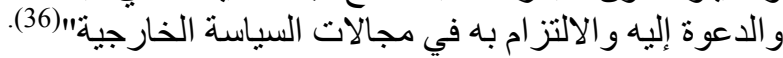

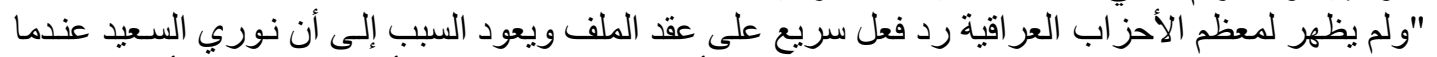

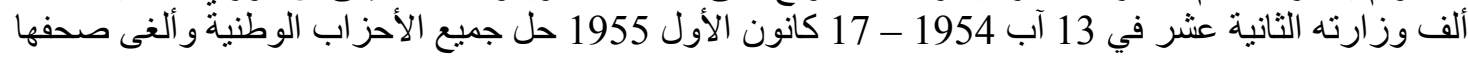

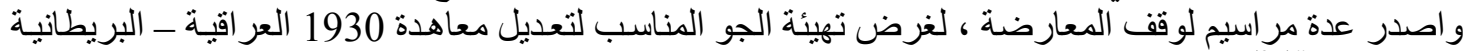

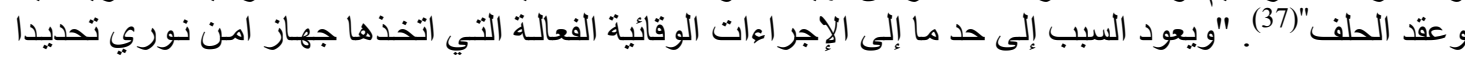

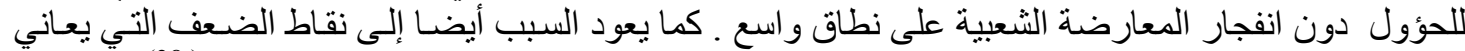

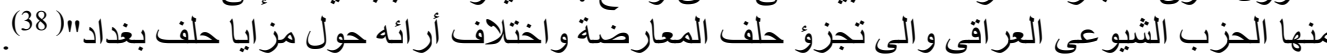

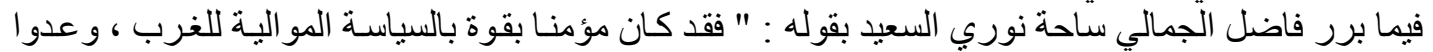

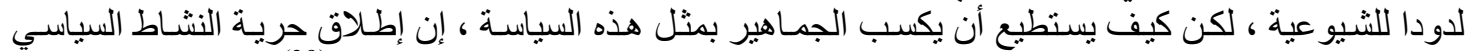

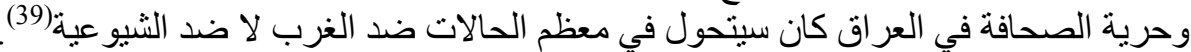


International Journal of Humanities and Social Sciences

website:www.ijohss.com

Email:editor@ijohss.com

ISSN: $2415-4822$

2020 لسبتمبر

العدد (15)

Volume (15) September 2020

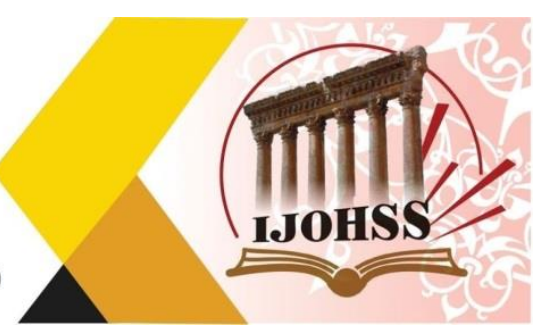

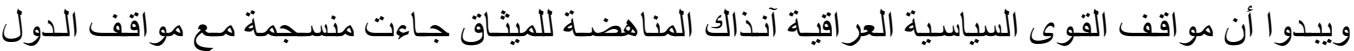

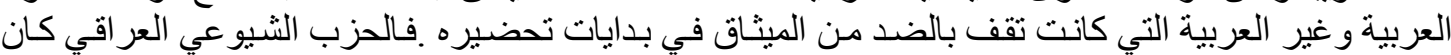

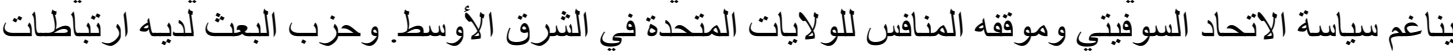

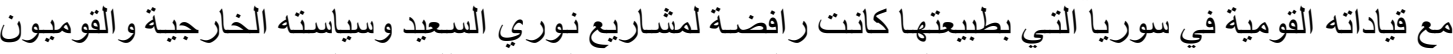

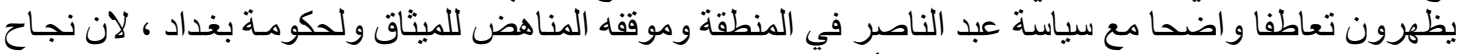

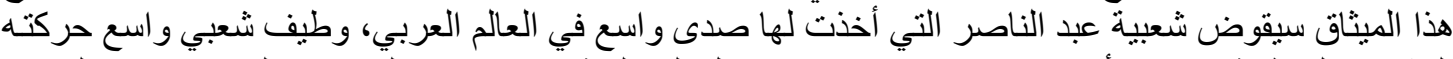

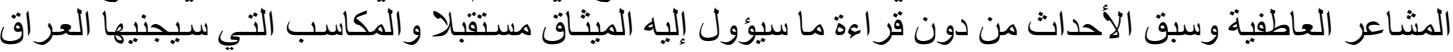

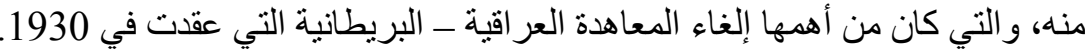

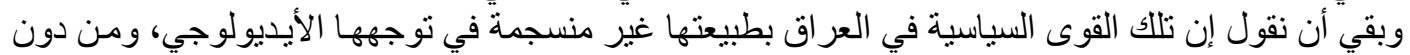

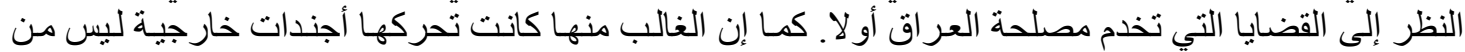

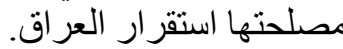

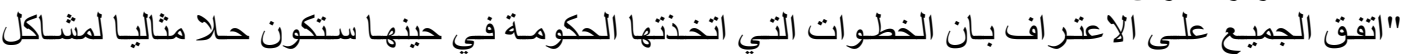

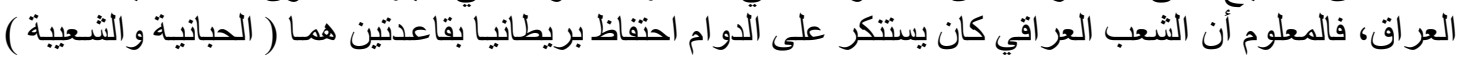

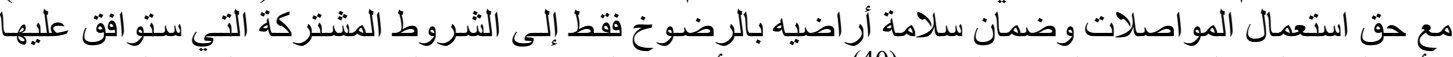

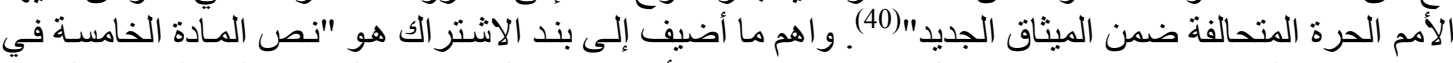

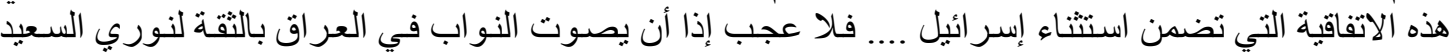

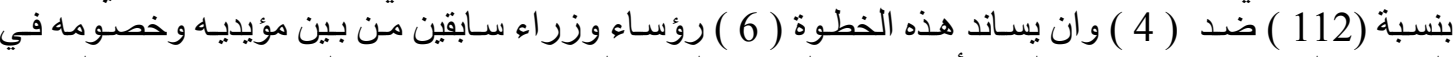

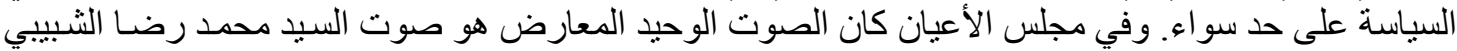

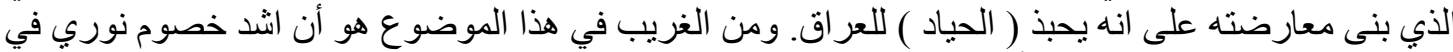

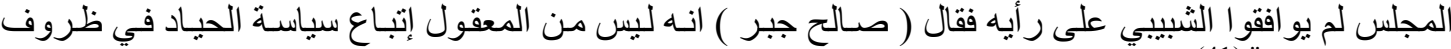

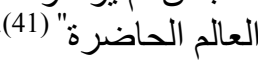

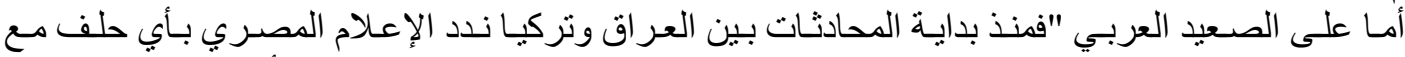

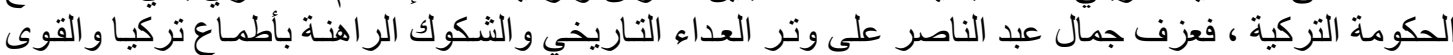

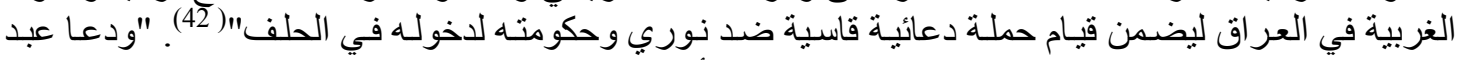

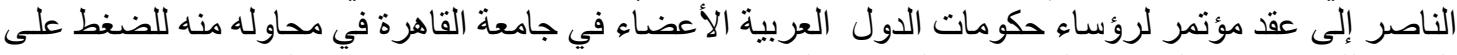

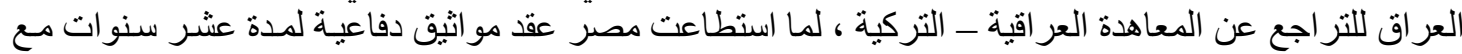

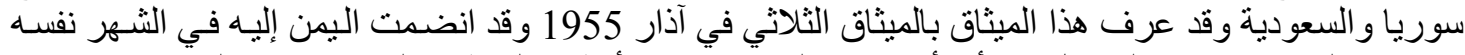

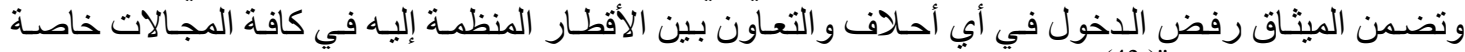

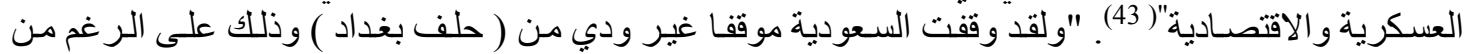

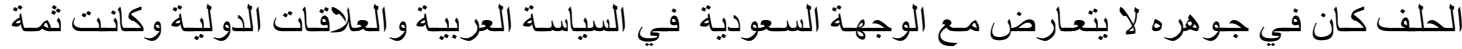

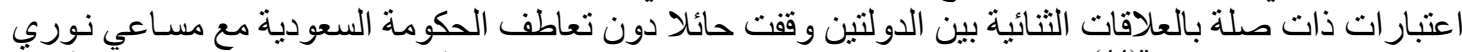

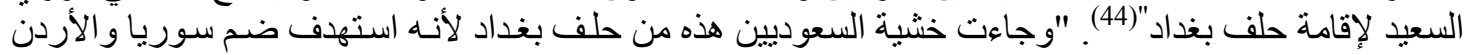

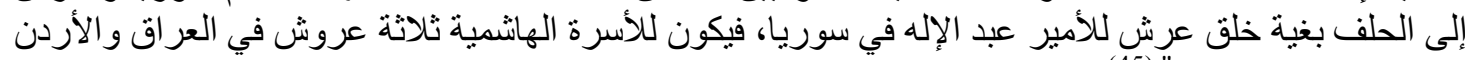

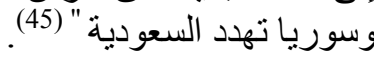

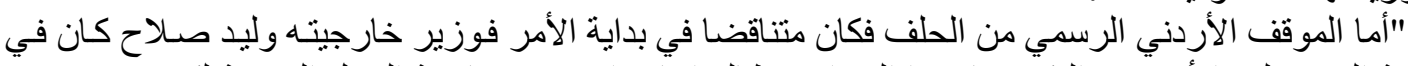

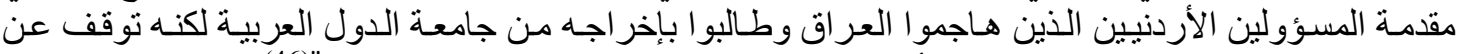

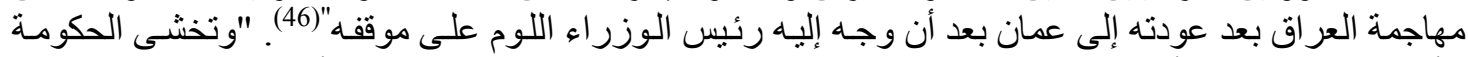

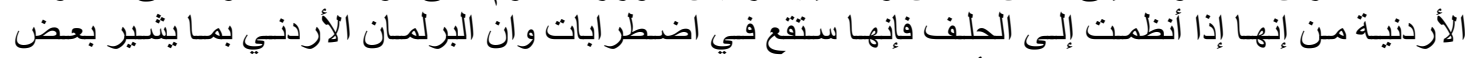

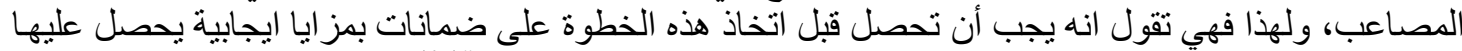

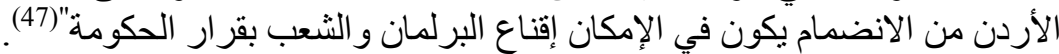

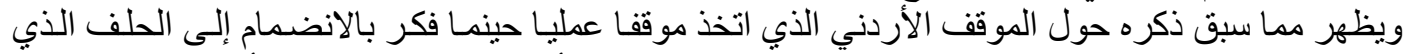

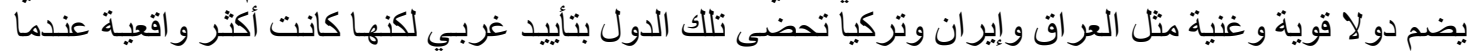

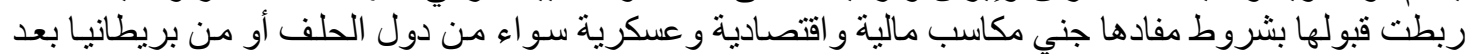


International Journal of Humanities and Social Sciences

website:www.ijohss.com

Email:editor@ijohss.com

ISSN: $2415-4822$

2020 لسبتهبر

العدد (15)

Volume (15) September 2020

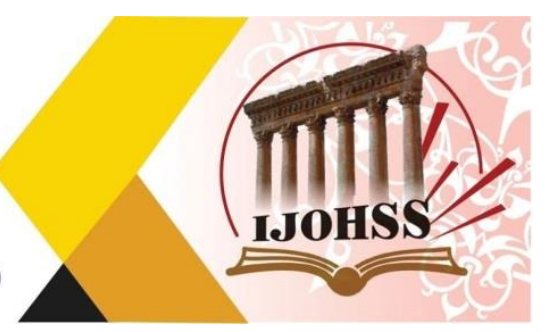

أن شعرت بان دول (حلف بغداد) كانت بحاجة إلى كسب الموقف الأردني إلى جانبها، و الحسال فان الأردن عندما

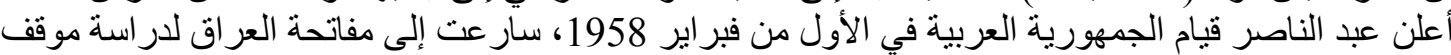

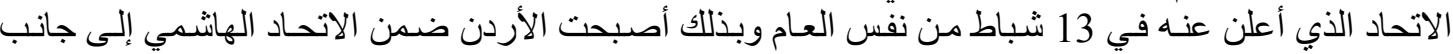

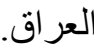

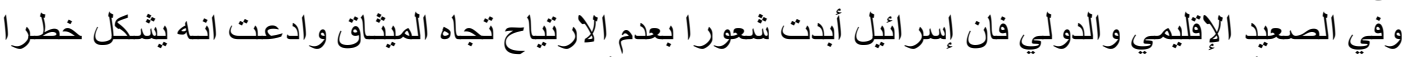

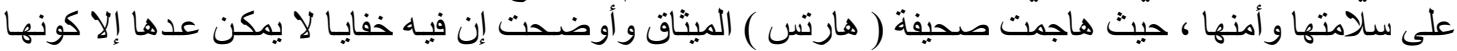

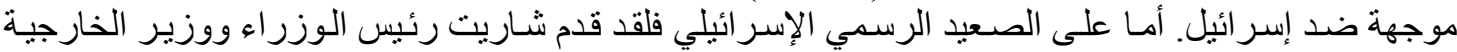

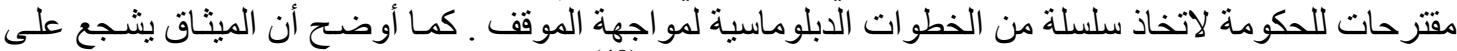

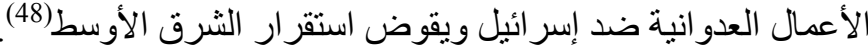

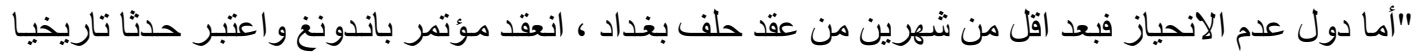

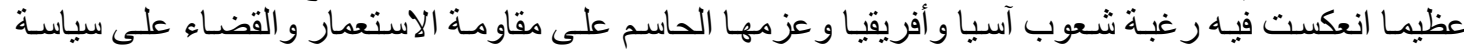

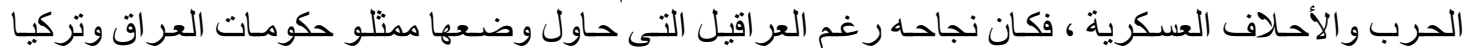

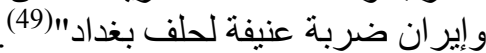

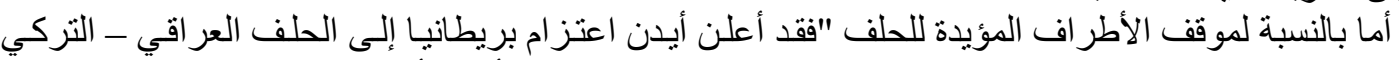

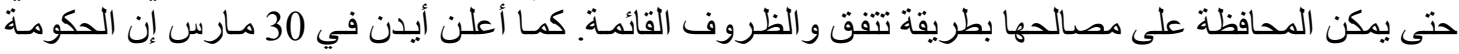

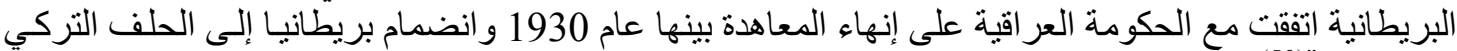

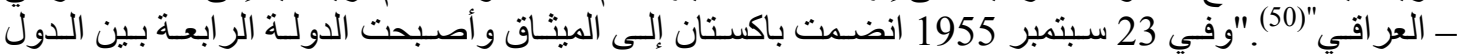

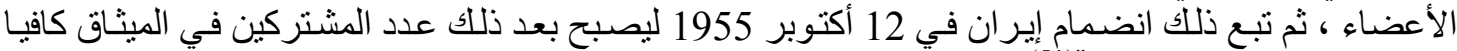

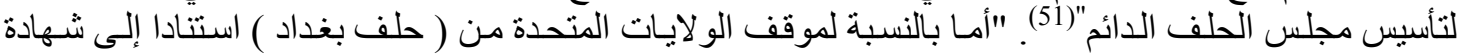

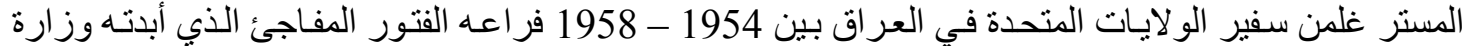

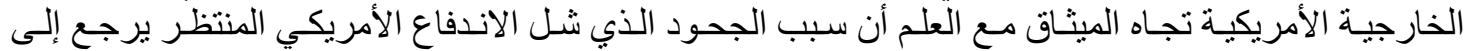

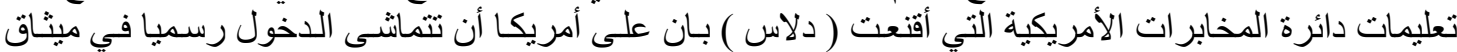

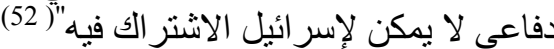

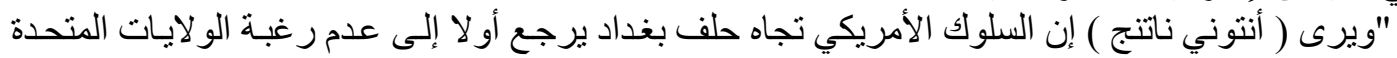

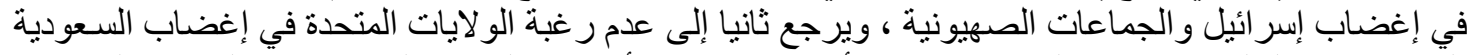

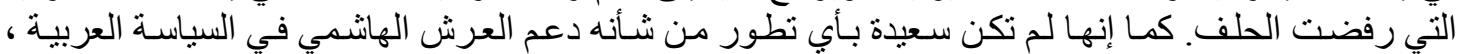

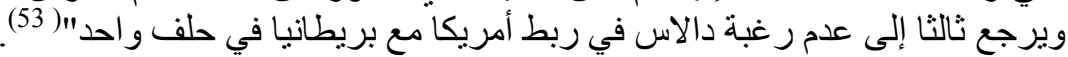

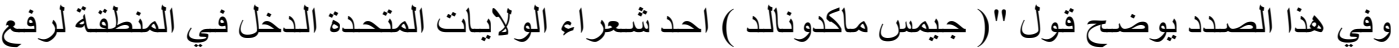

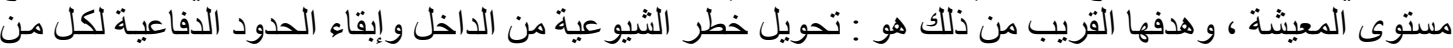

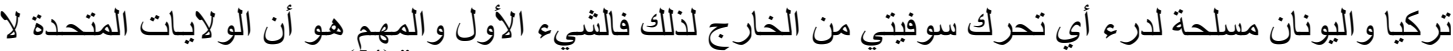

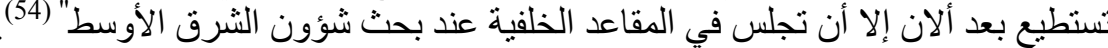

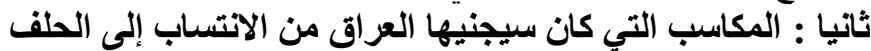

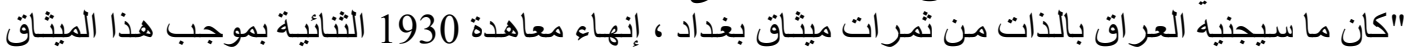

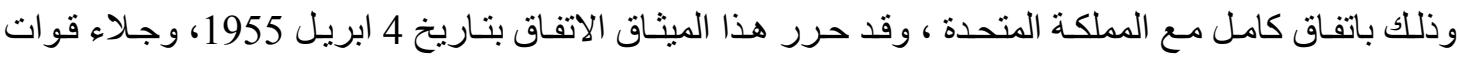

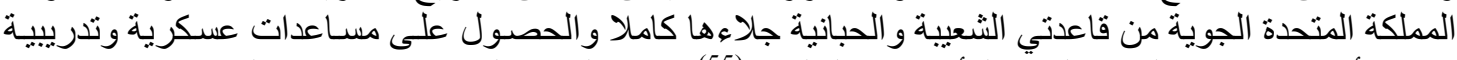

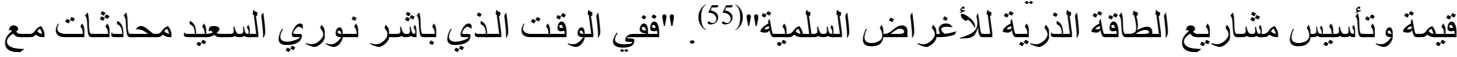

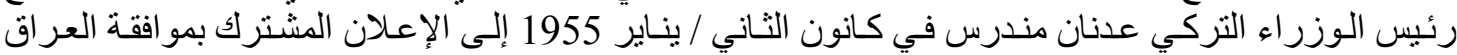

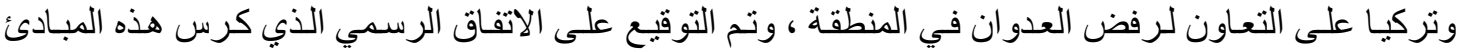

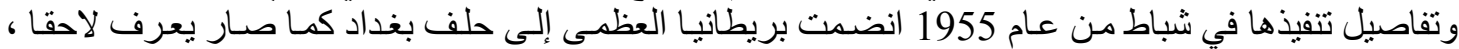

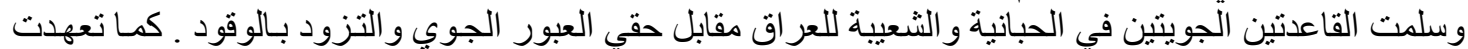

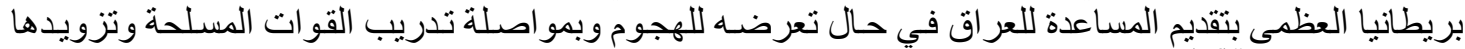

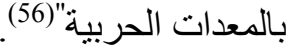


International Journal of Humanities and Social Sciences

website:www.ijohss.com

Email:editor@ijohss.com

ISSN: $2415-4822$

2020 لسبتمبر

العدد (15)

September 2020

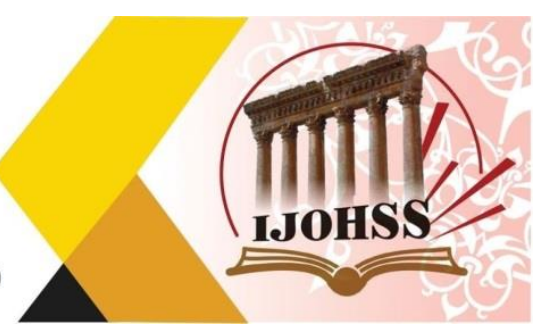

يذكر غلمن، "مما لا شك فيه أن براعة مندرس وطريقته المحبية في الإقتاع لعبت دور ها في ذلك الكي ، إلا إني

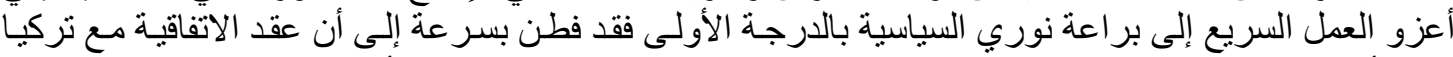

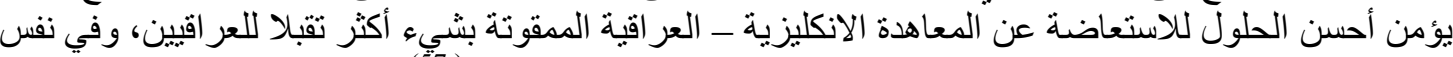

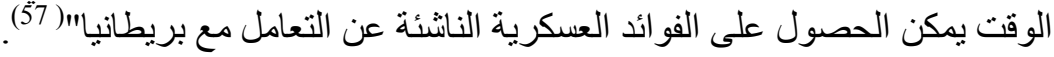

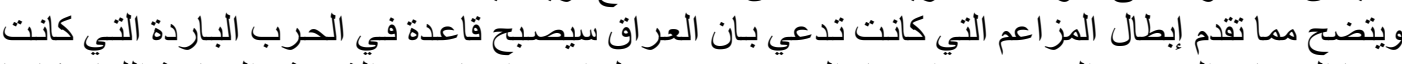

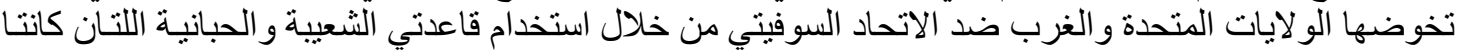

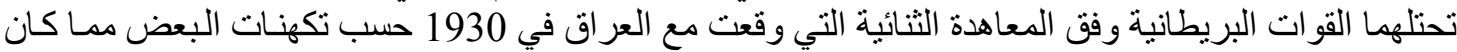

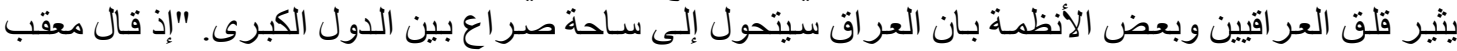

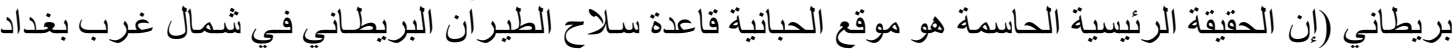

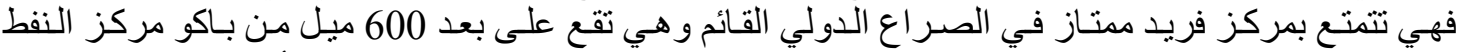

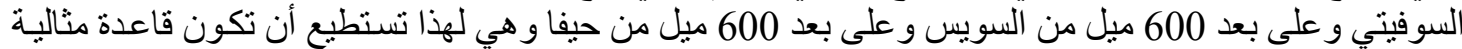

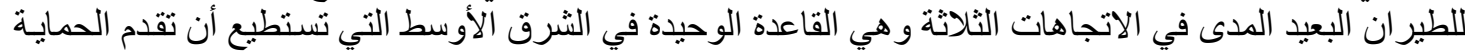

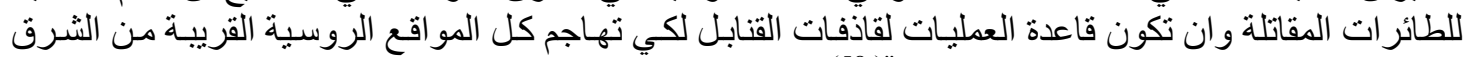

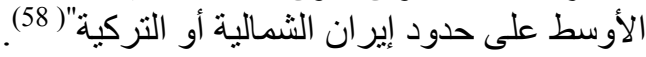

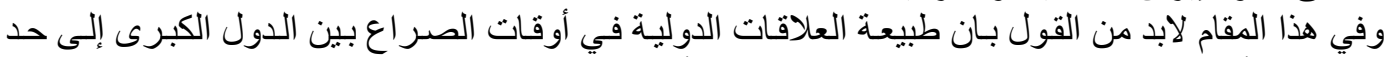

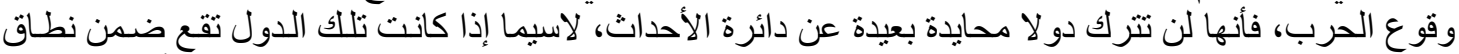

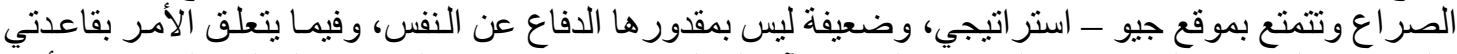

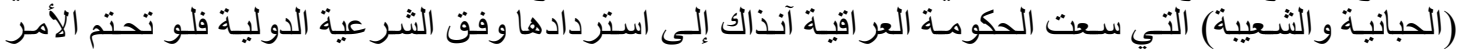

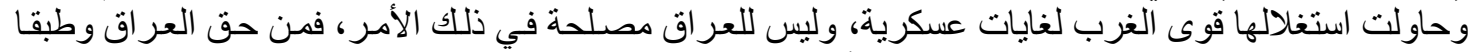

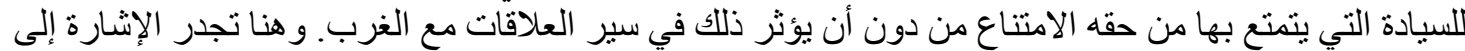

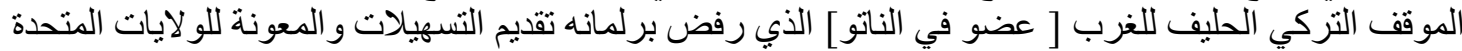

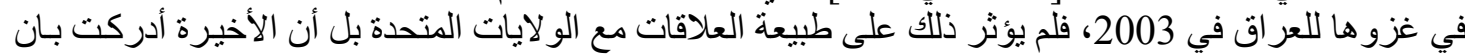

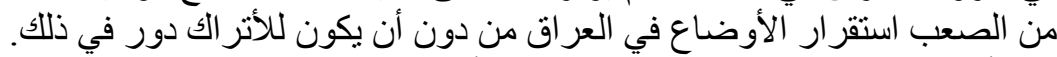

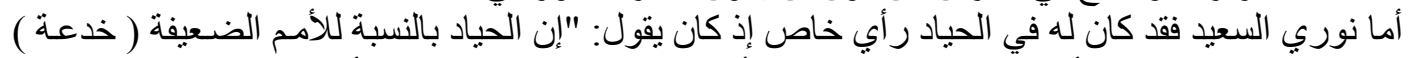

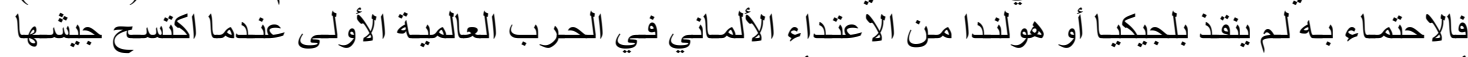

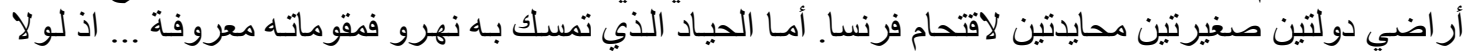

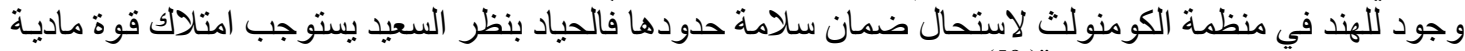

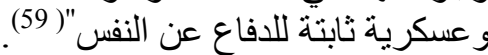

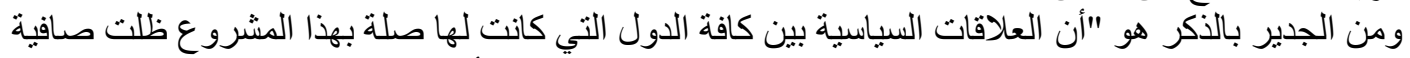

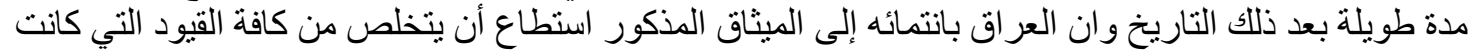

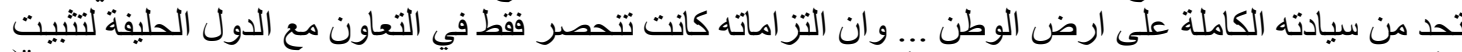

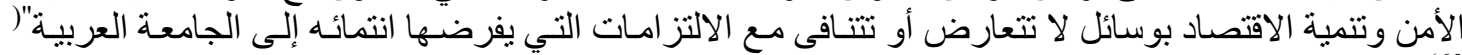

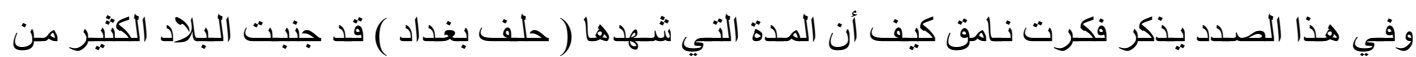

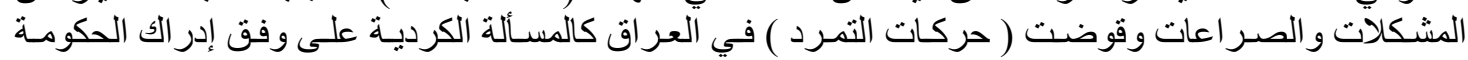

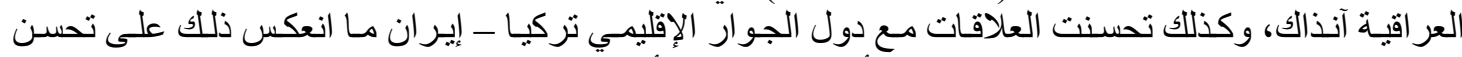

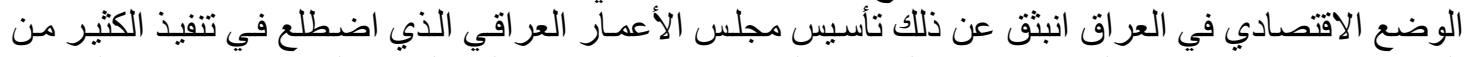

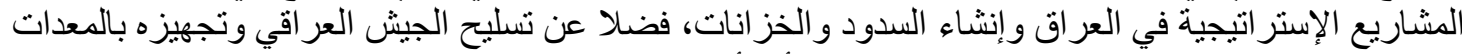

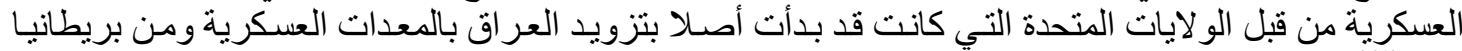

أما الدول الآسيوية الأخرى" فقد وجدت في نصوص الميثاق روح التضامن و التعاون الأخوي التي يحتمها،

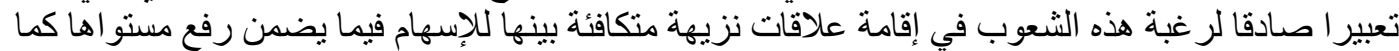

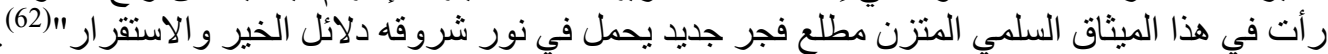


International Journal of Humanities and Social Sciences

website:www.ijohss.com

Email:editor@ijohss.com

ISSN: $2415-4822$

\author{
2020 لسبتمبر \\ (15) (15) \\ Volume (15) September 2020
}

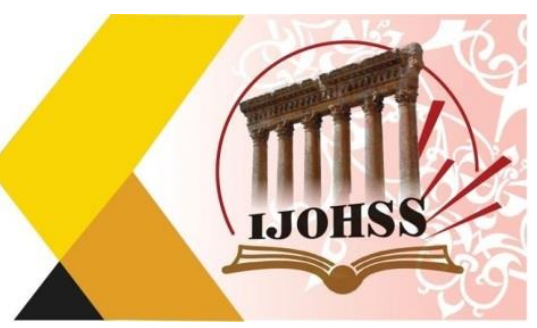

\title{
المبحث الثالث
}

المتغيرات السياسية في منطقة الثرق الأوسط وانعكاساتها على الحلف

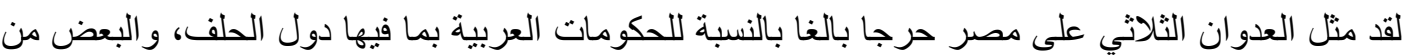

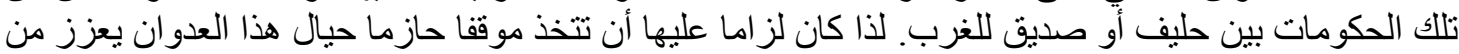

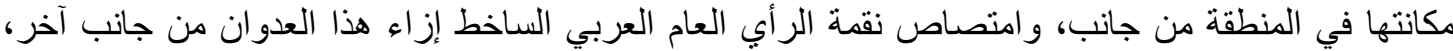

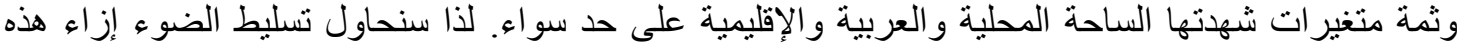
المتغيرات من خلال هذا المبحث الذي قسم على مطلبين فالأول: المتغير العر اقي اثر الثي الهيار النظام الملكي وقيام

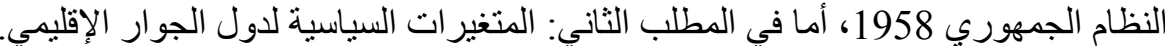

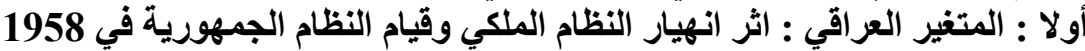

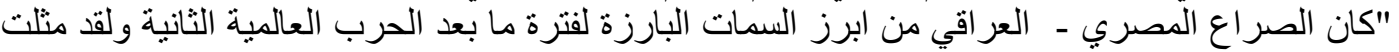

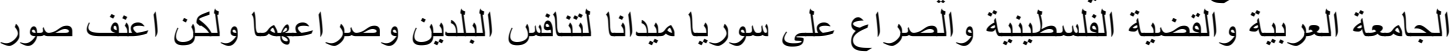

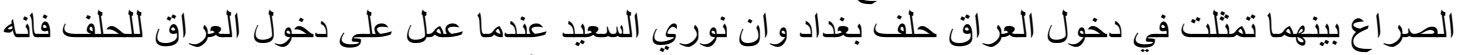

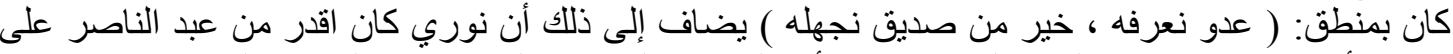

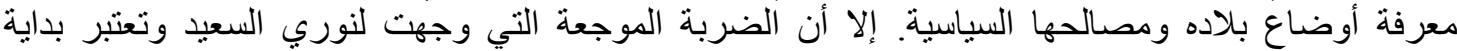

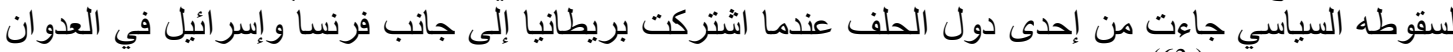

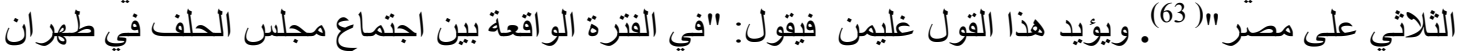

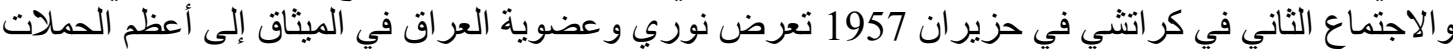

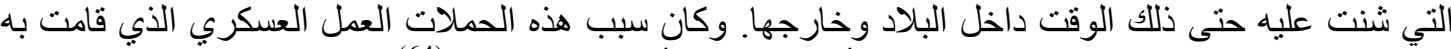

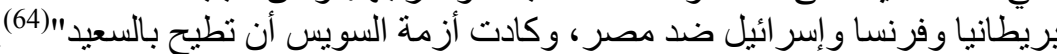

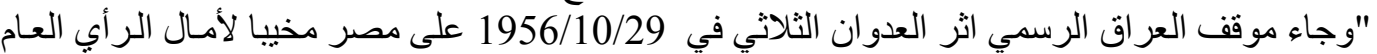

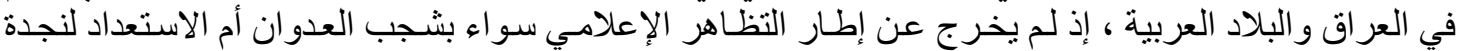

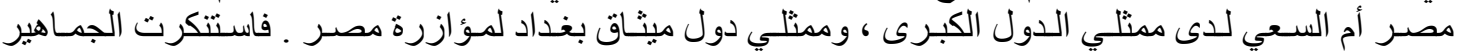

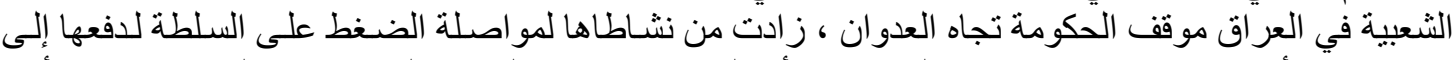

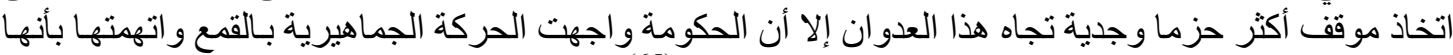

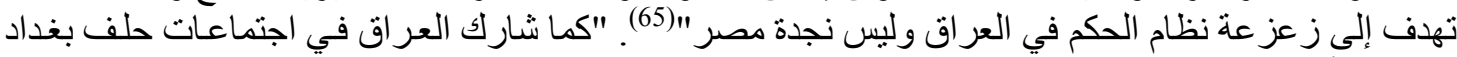

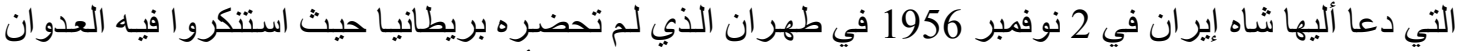

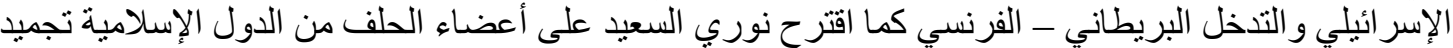

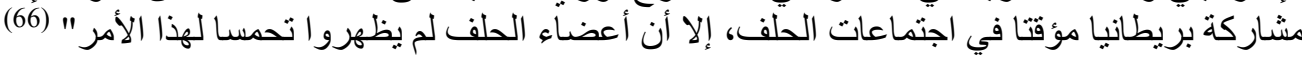

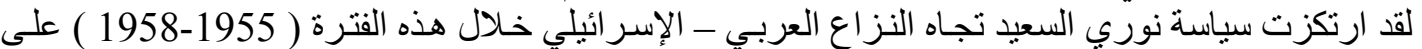

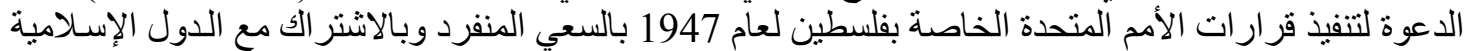

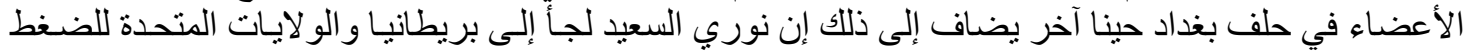

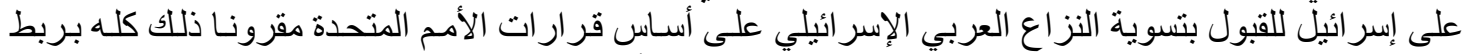

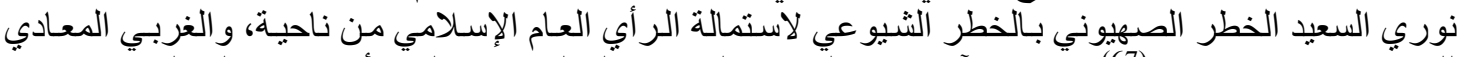

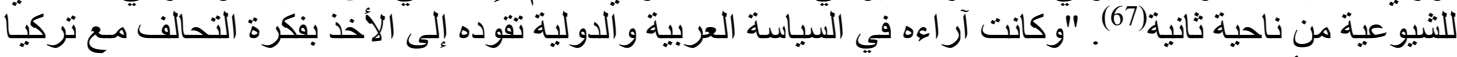

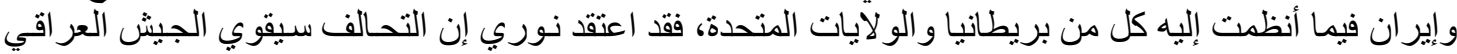

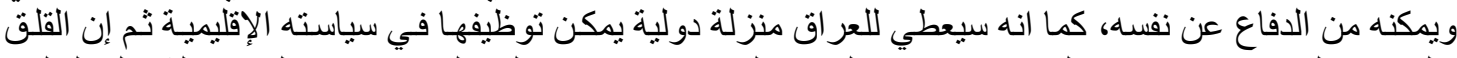

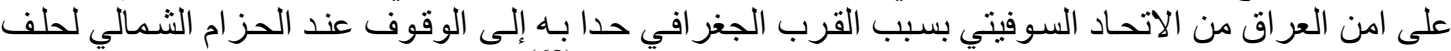

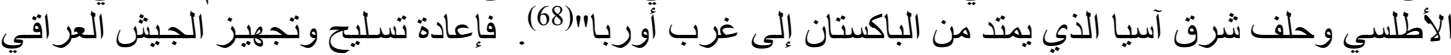

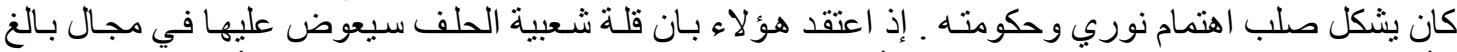

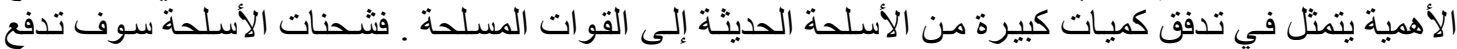

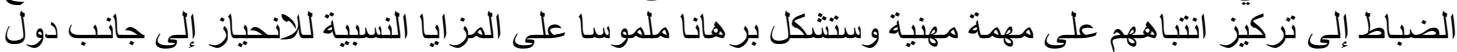


International Journal of Humanities and Social Sciences

website:www.ijohss.com

Email:editor@ijohss.com

ISSN: $2415-4822$

2020 لسبتمبر

العدد (15)

Volume (15)

September 2020

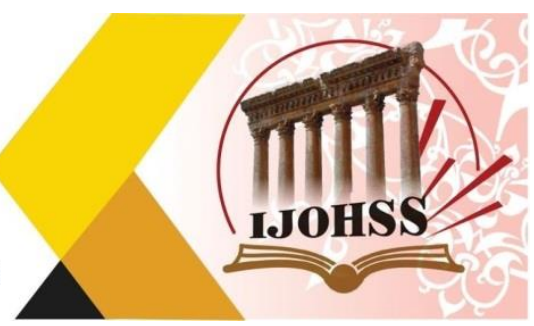

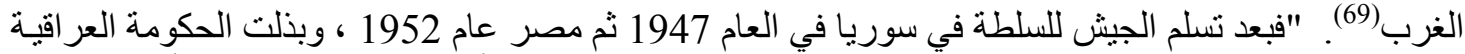

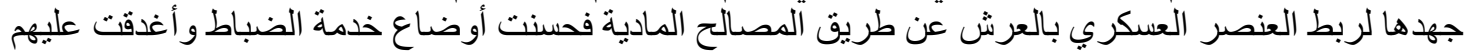

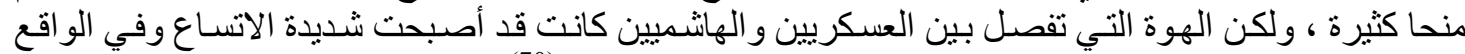

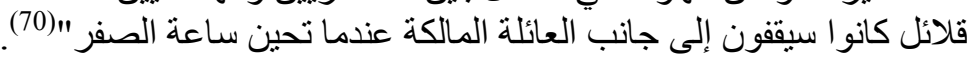

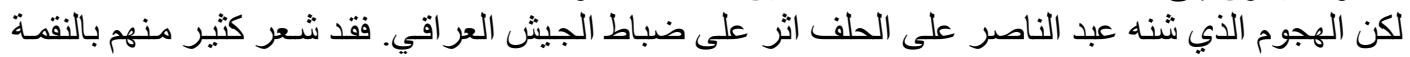

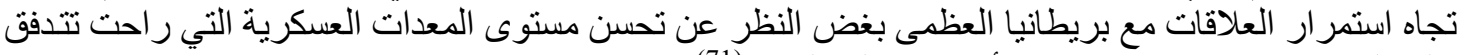

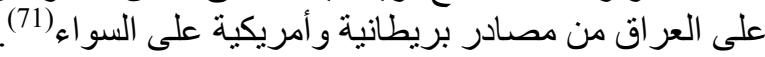

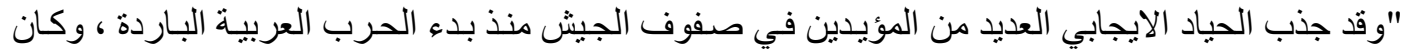

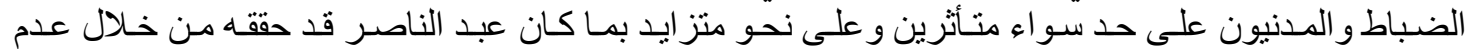

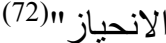

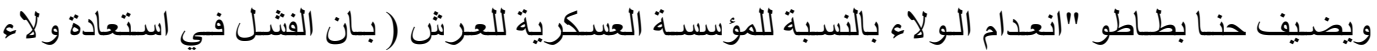

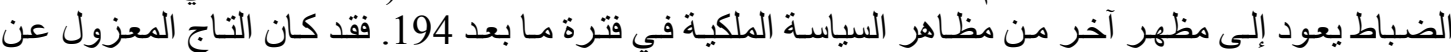

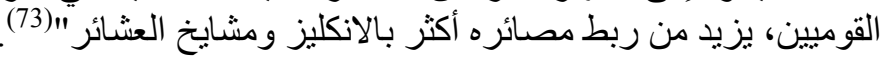

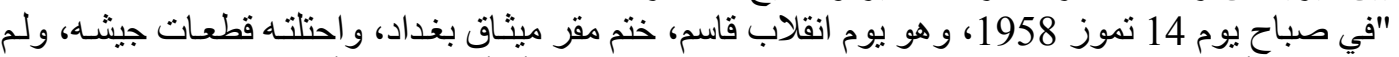

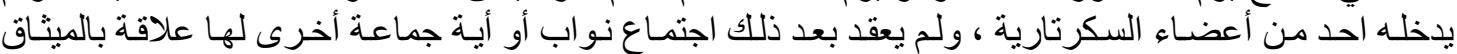

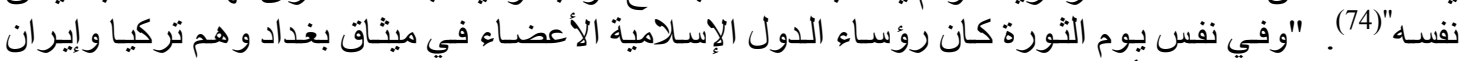

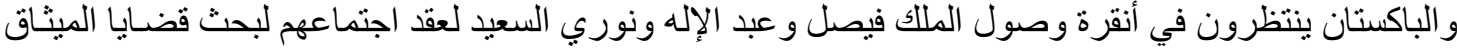

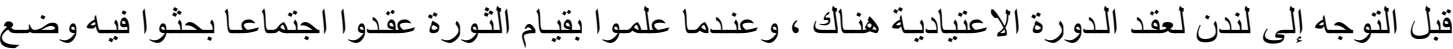

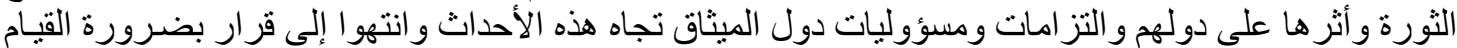

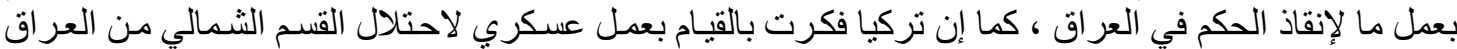

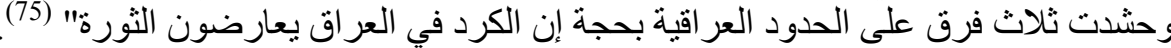

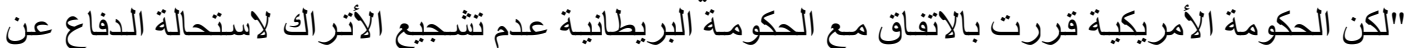

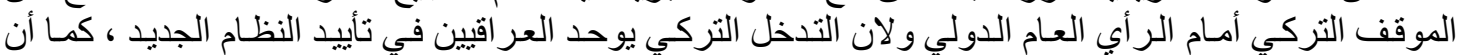

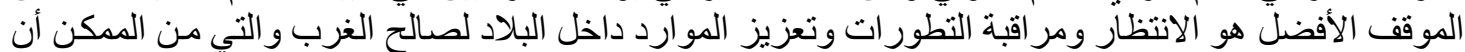

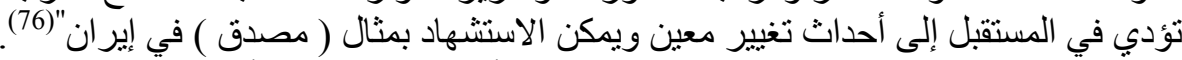

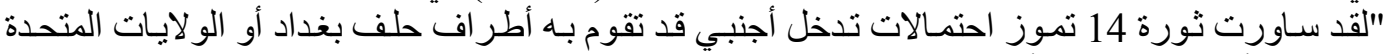

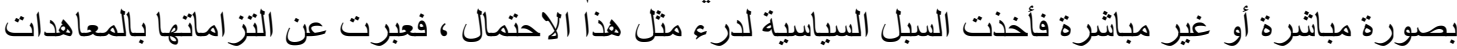

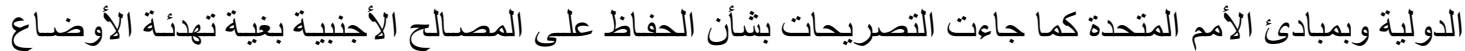

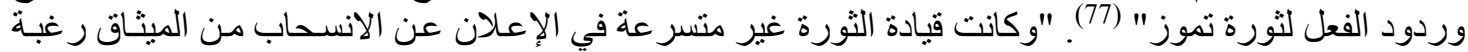

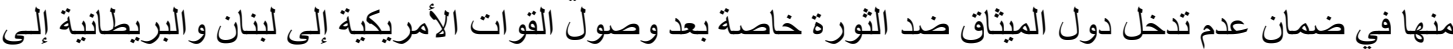

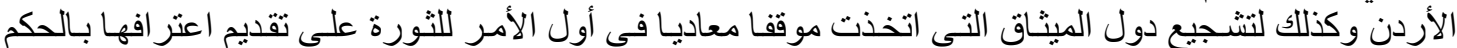

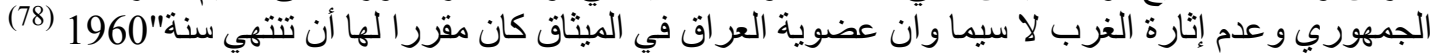

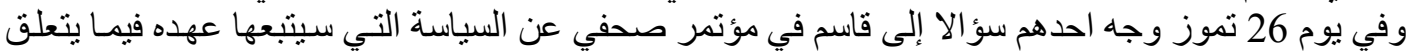

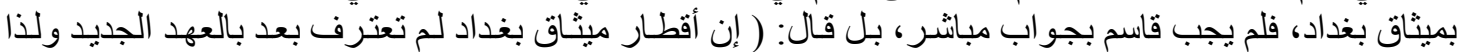

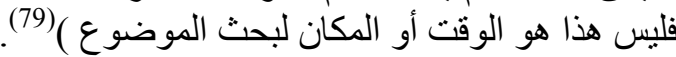

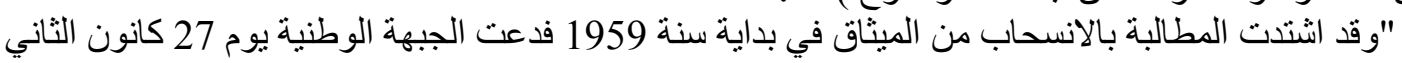

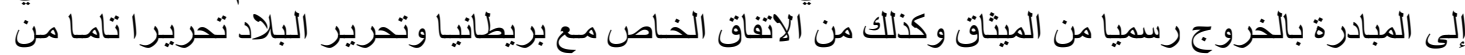

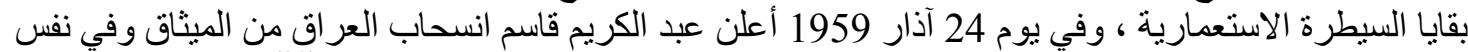

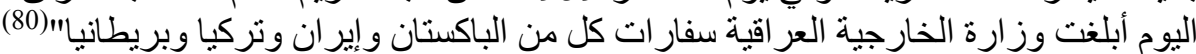

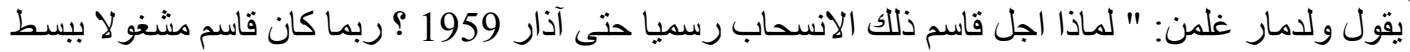

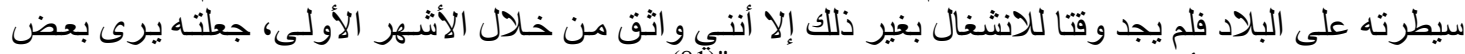
الفائدة في عدم اتخاذ أي قرار للانسحاب عن الميثاق تماما"(81) 
International Journal of Humanities and Social Sciences

website:www.ijohss.com

Email:editor@ijohss.com

ISSN: $2415-4822$

2020 لسبتهبر

العدد (15)

Volume (15) September 2020

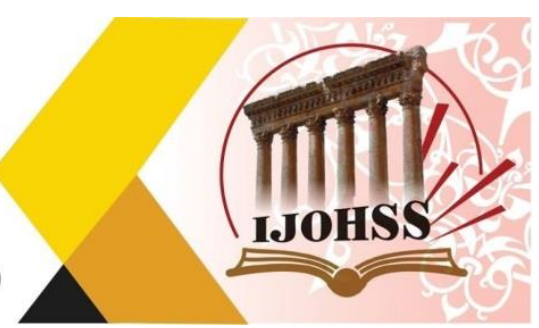

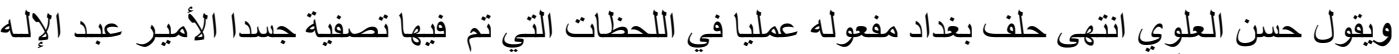

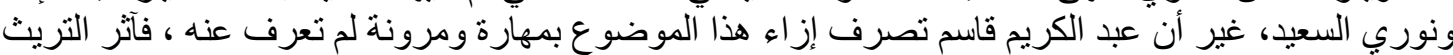

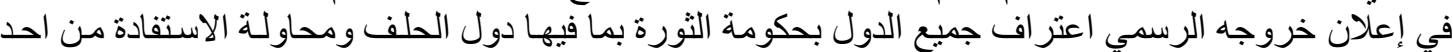

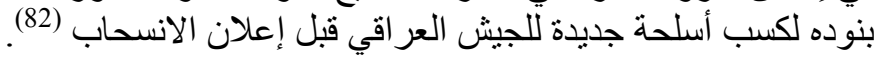

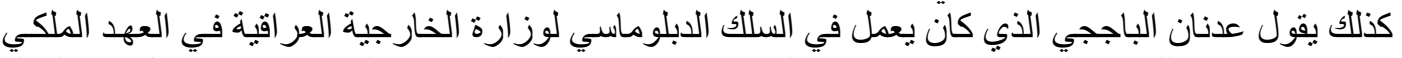

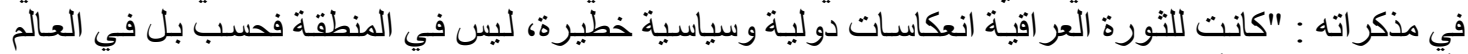

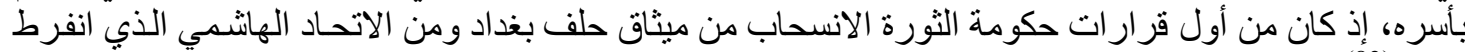
عقده"(83)

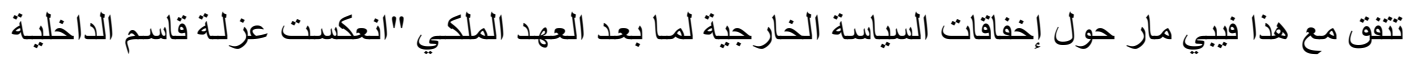

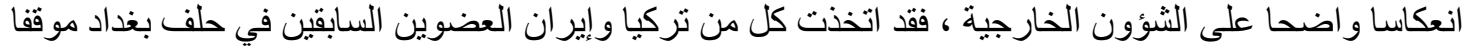

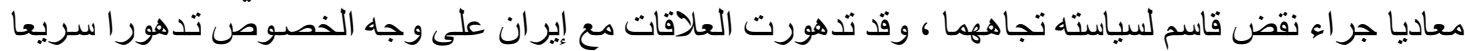

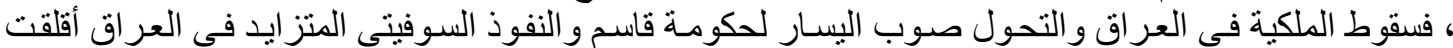
الثناه"(84)

ثانيا: المتغيرات السياسية لدول الجوار الإقليمي

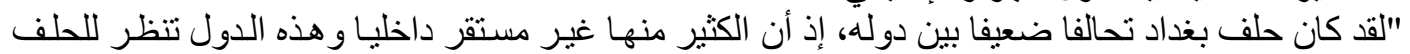

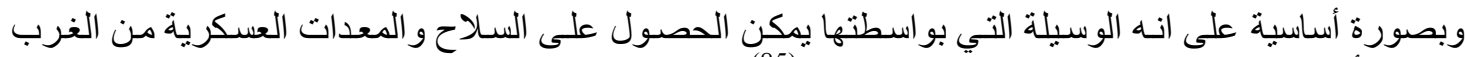

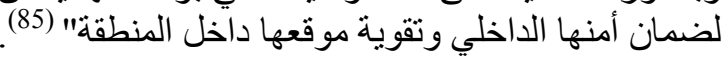

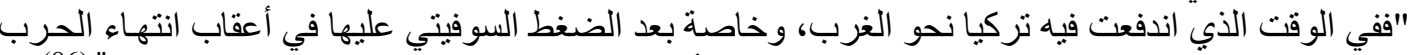

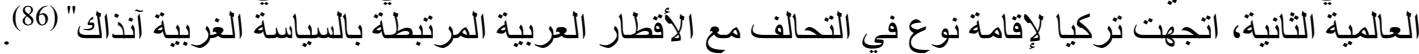

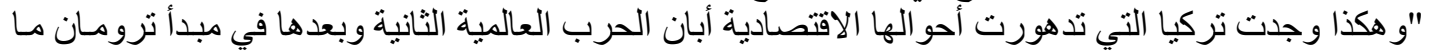

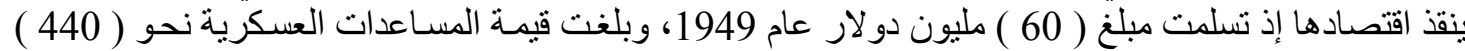

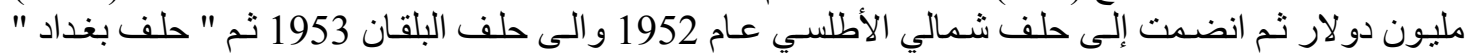

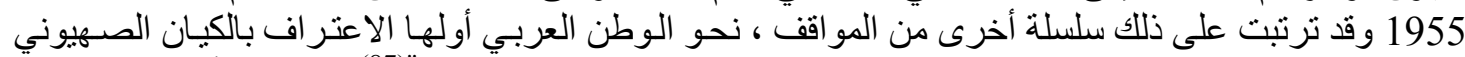

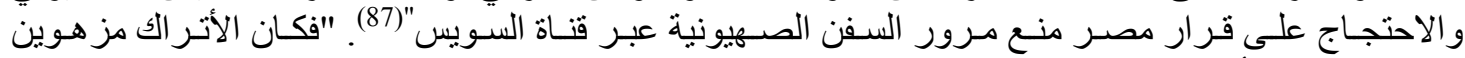

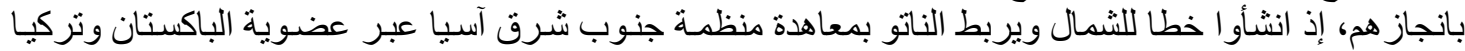

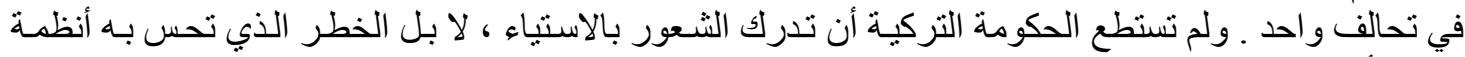

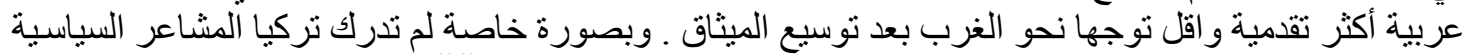

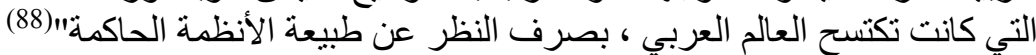

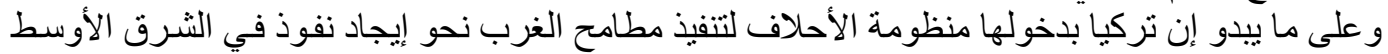

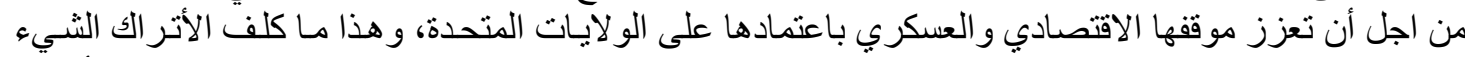

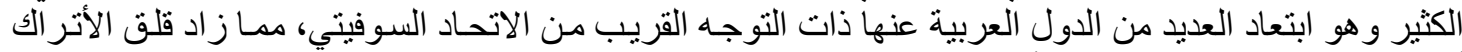

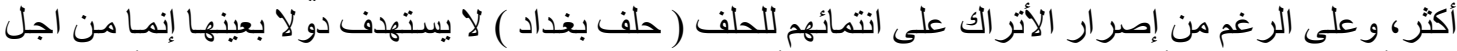

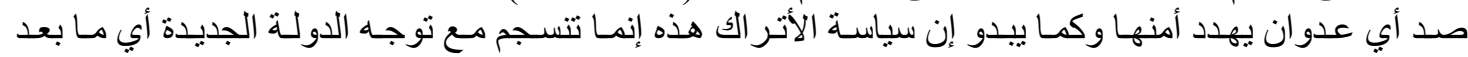

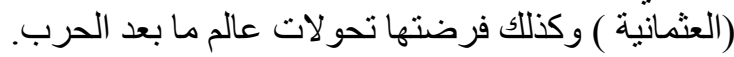

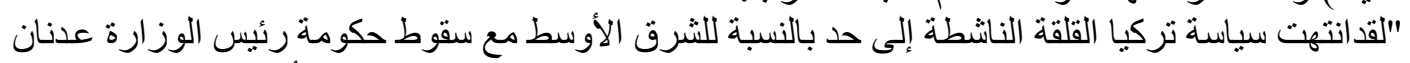

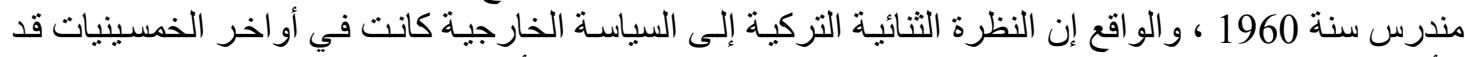

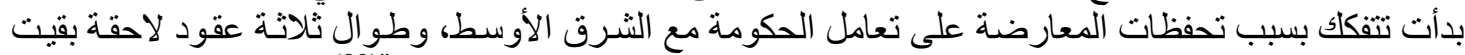

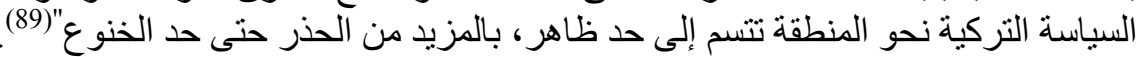

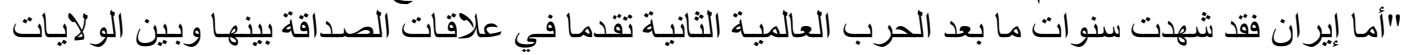

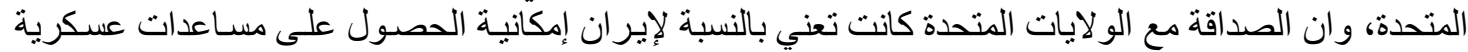

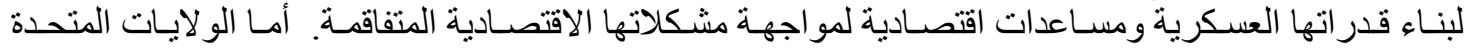

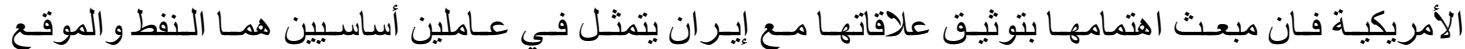
الاستر اتيجي" (90). 
International Journal of Humanities and Social Sciences

website:www.ijohss.com

Email:editor@ijohss.com

لسبتهبر 2020

العدد (15)

ISSN: 2415 - 4822

Volume (15)

September 2020

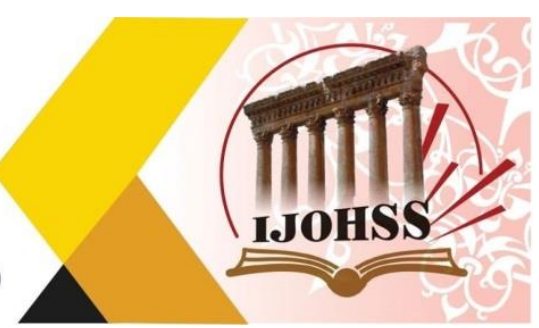

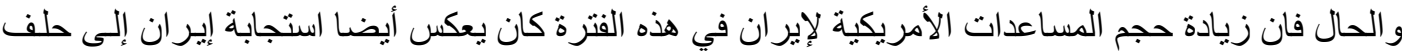

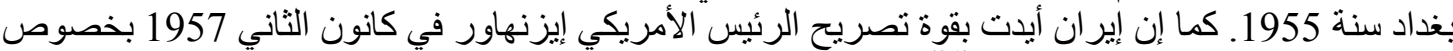

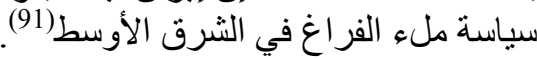

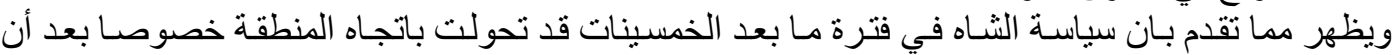

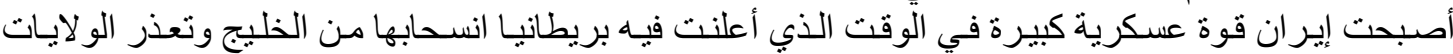

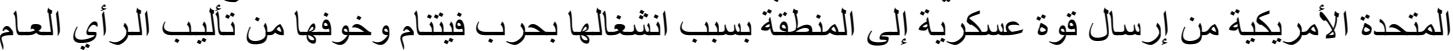

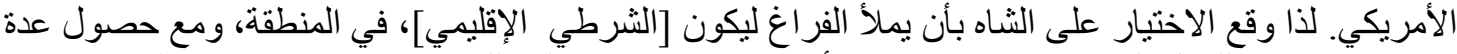

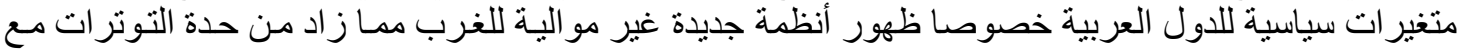

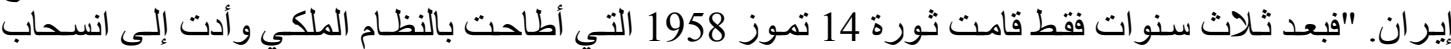

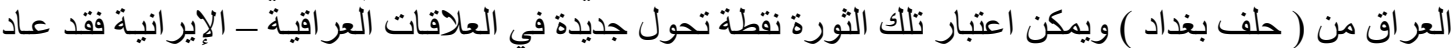

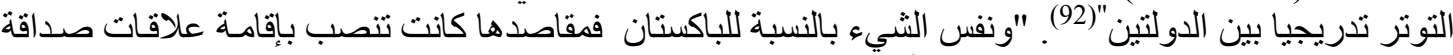

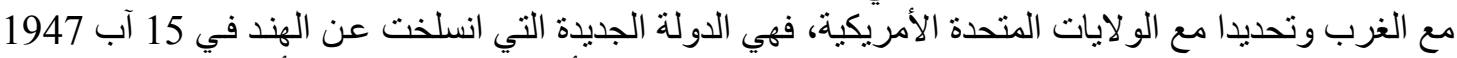

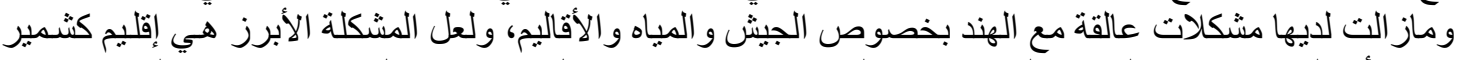

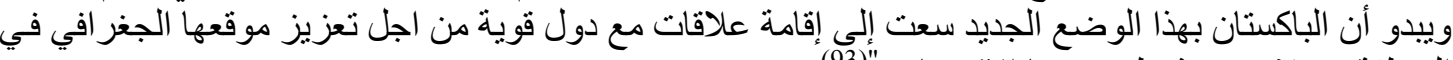

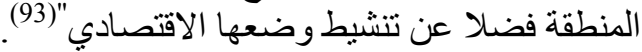

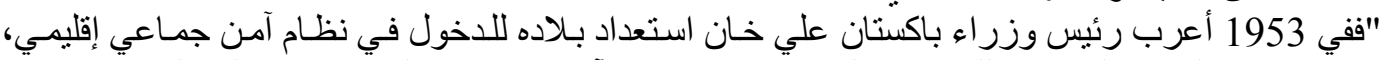

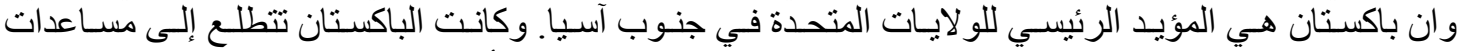

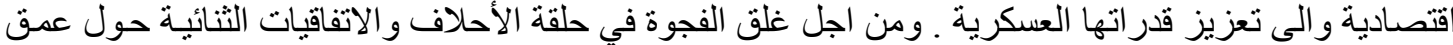

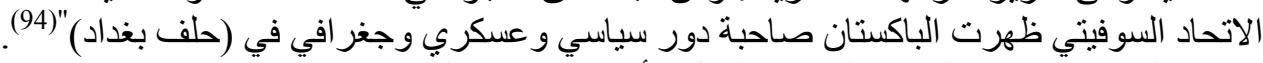

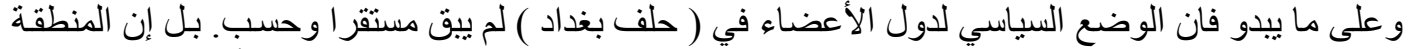

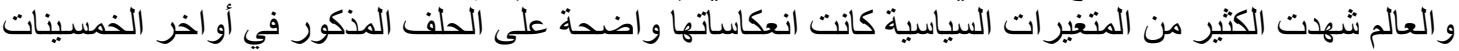

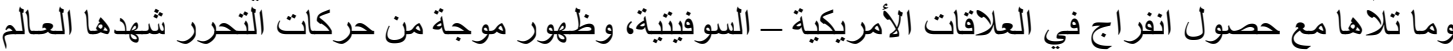

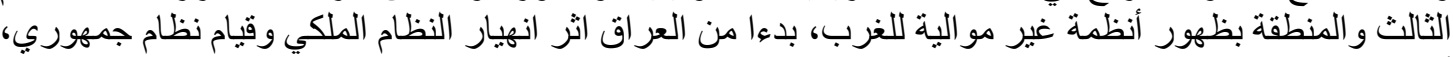

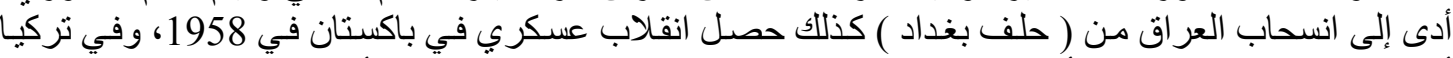

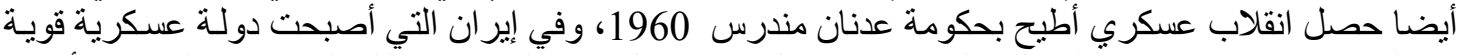

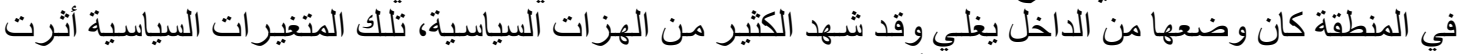

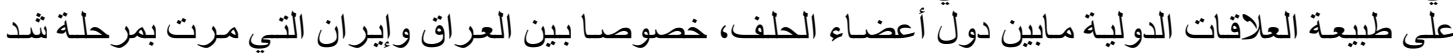
وجذب، و التوترات استمرت في تصاعد في مرحلة الستينيات وما تلاها.

الخاتمة

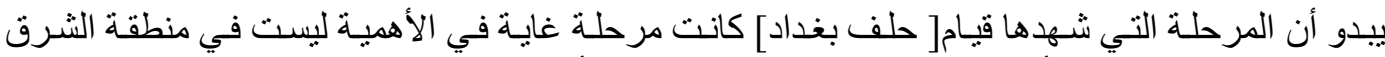

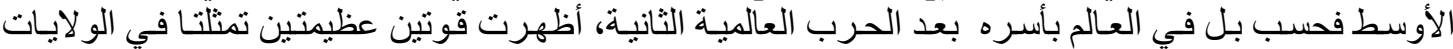

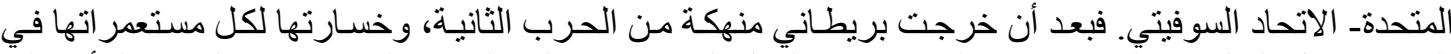

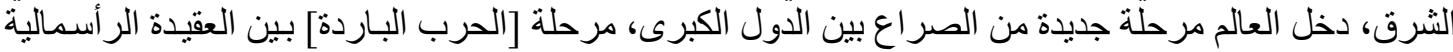

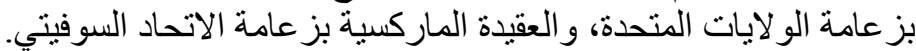

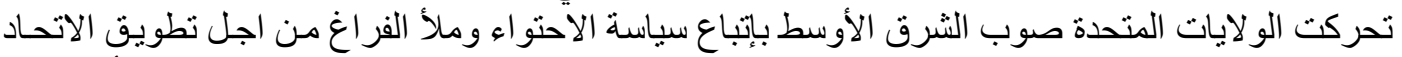

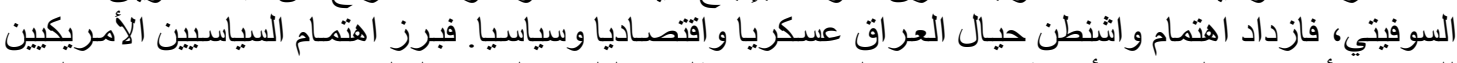

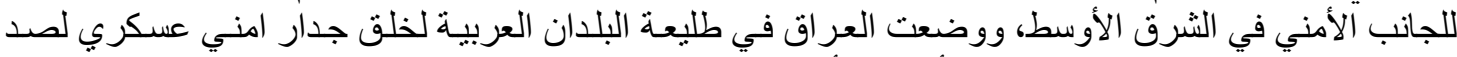

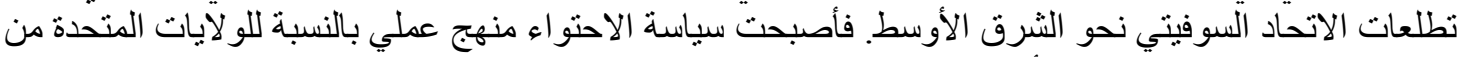

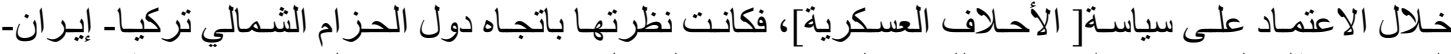

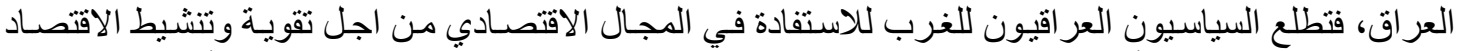

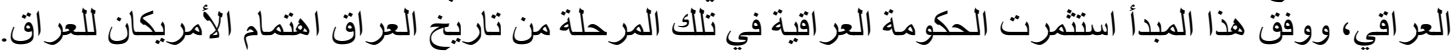

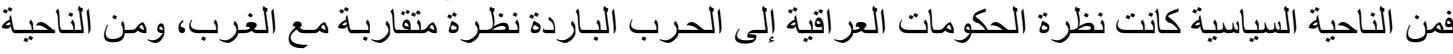




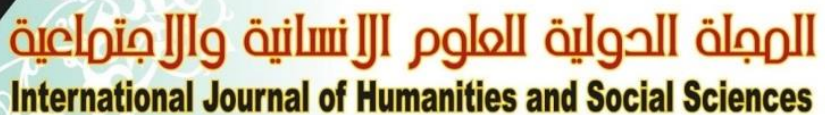

website:www.ijohss.com

Email:editor@ijohss.com

ISSN: $2415-4822$

2020 سبتمبر

(15) العدد (15)

Volume (15)

September 2020

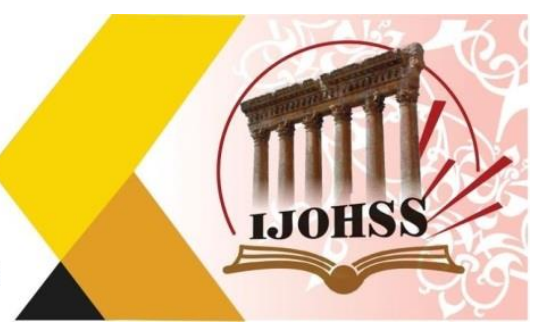

الاقتصادية حصل العر اق على قروض من البنك الدولي قدمته الو لايات المتحدة، وقرضـا آخر لمشروع الثرثار في

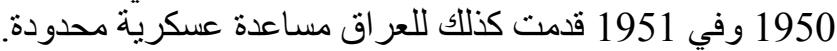

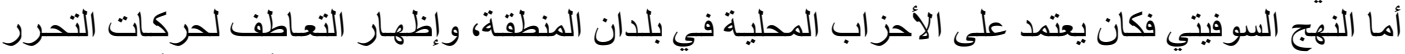

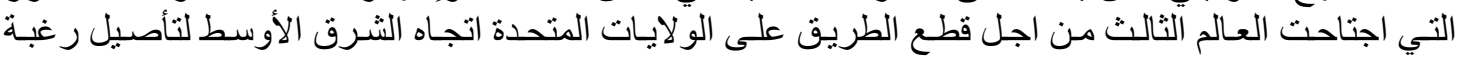

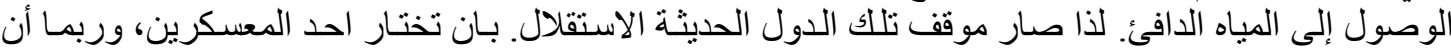

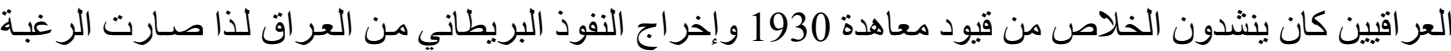

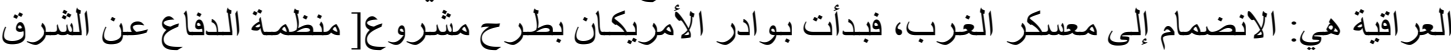

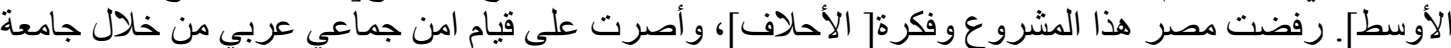
الدول العربية بعيدا عن سياسة الأحلاف العسكرية.

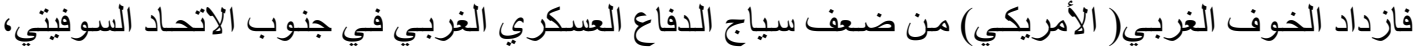

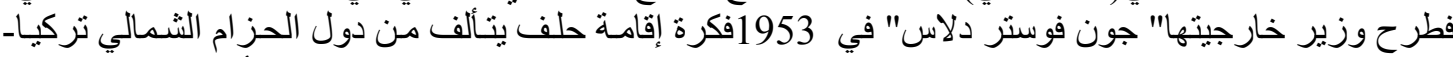

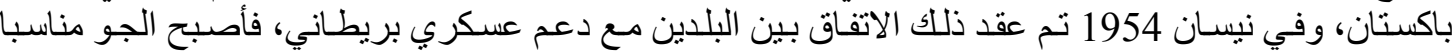

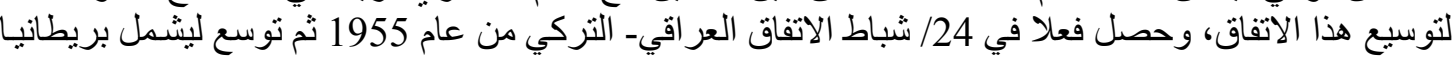

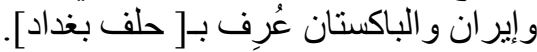

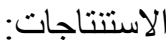

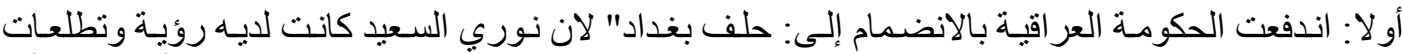

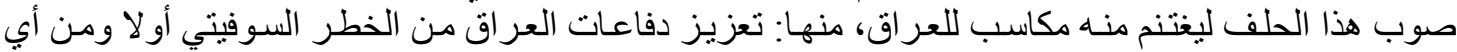

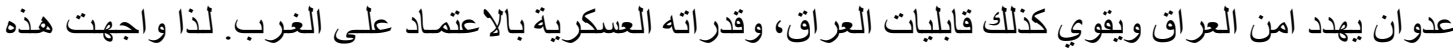

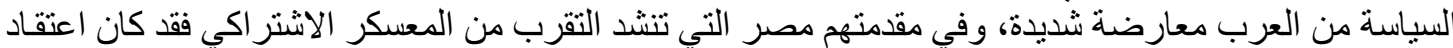

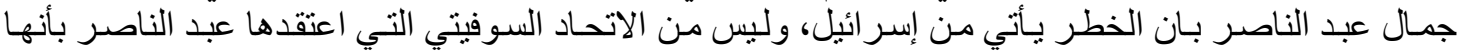

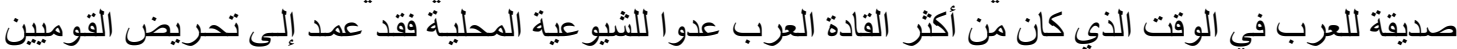

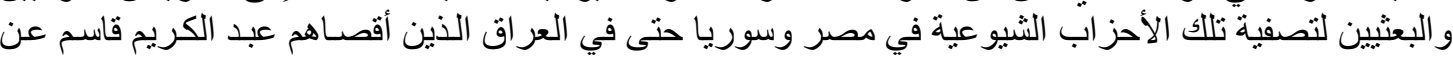

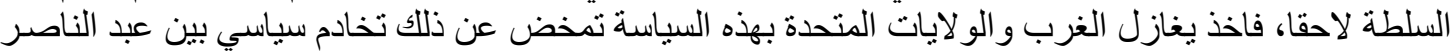

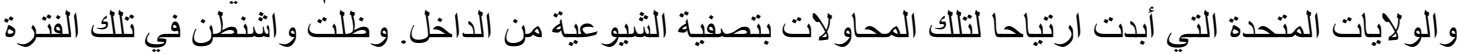

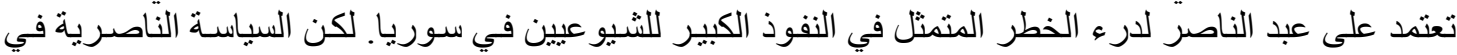

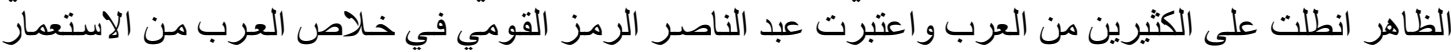

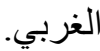
ثانيا: خلق علاقات قوية ومتينة مع دول الجوار الإقليمي: تركيا- إيران من خـلال [حلف بغداد] وهو الأمر الذي

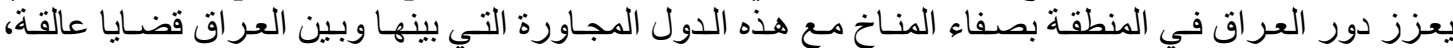

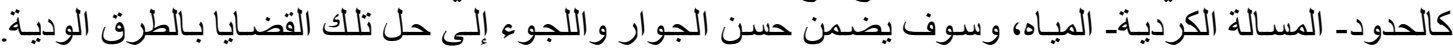

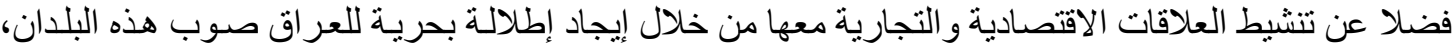

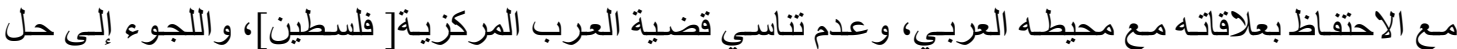

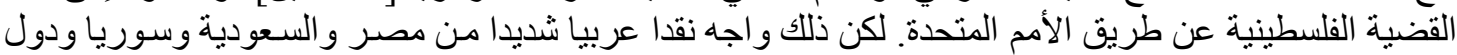

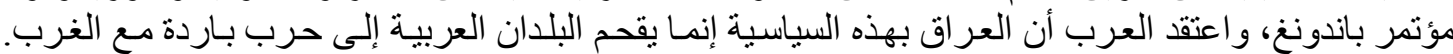

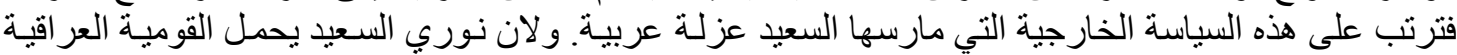

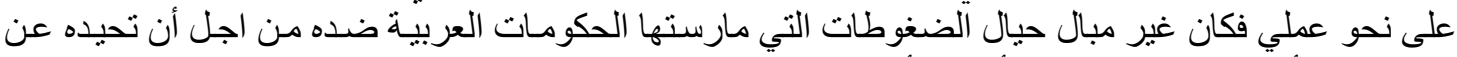

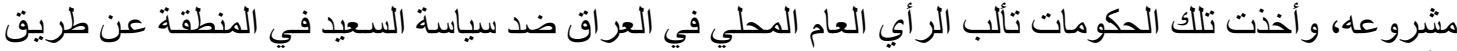
الأحز اب السياسية القومية، و اليسارية.

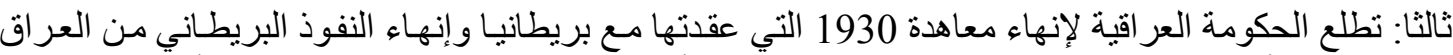

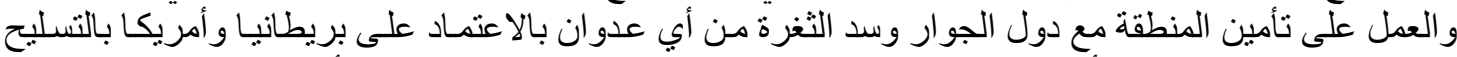

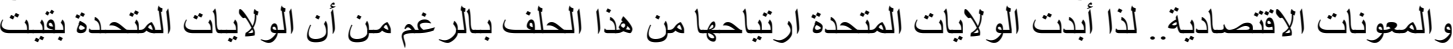

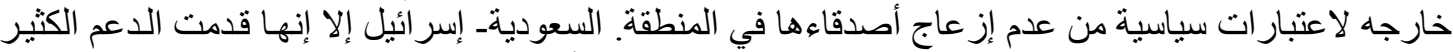

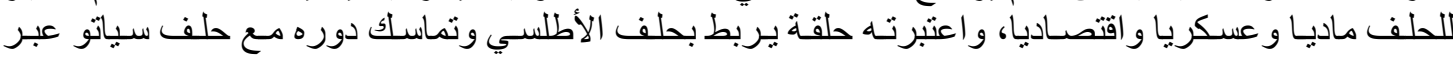


International Journal of Humanities and Social Sciences

website:www.ijohss.com

Email:editor@ijohss.com

ISSN: $2415-4822$

العدد (15) ل 2020

Volume (15) September 2020

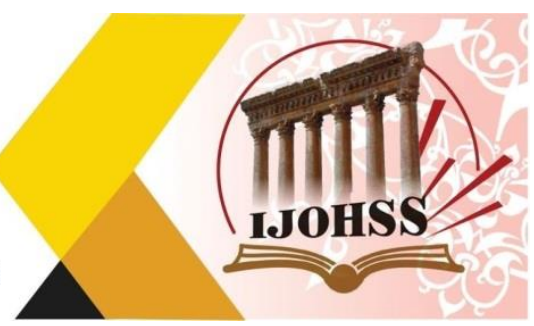

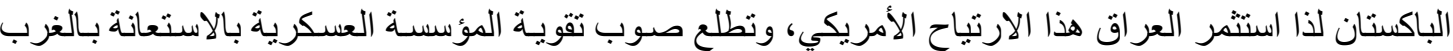

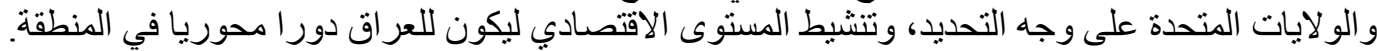

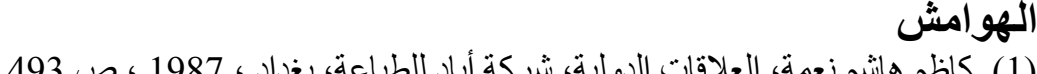

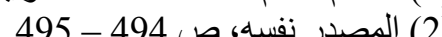

(3) محسن محمد المتولي العربي، نوري باثا السعيد من البداية إلى النهاية، الدار العربية للموسوعات، بيروت، 2005 ،

(4) خالدة أبلال الجبوري، الأبعاد السياسية للحكم الهاشمي ( 1941 - 1958 )، محاكاة الدراسات والنشر والتوزيع،

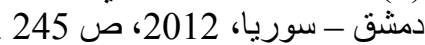

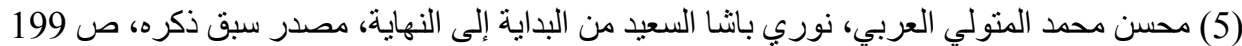

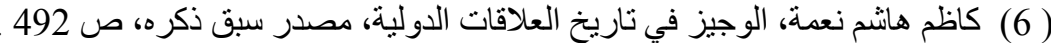

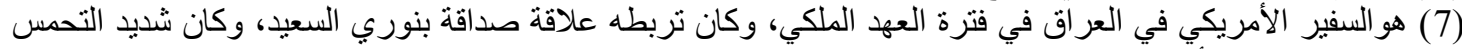

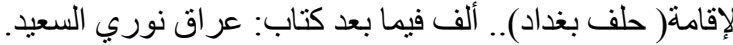

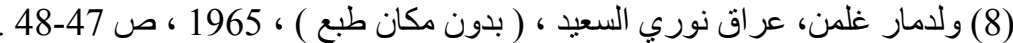

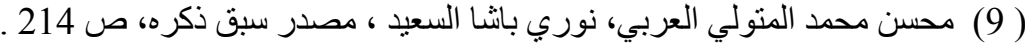

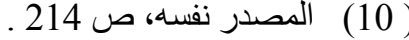

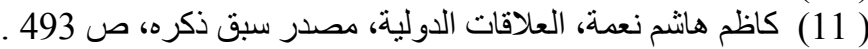

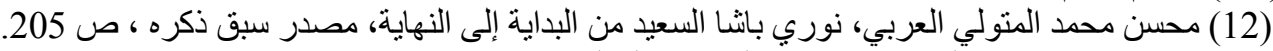

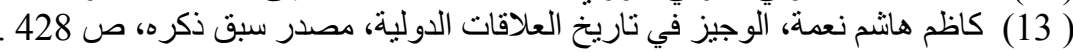

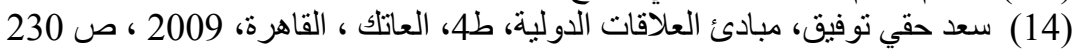

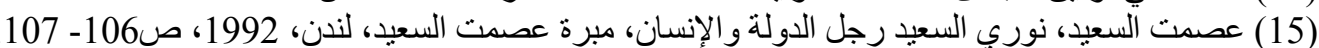

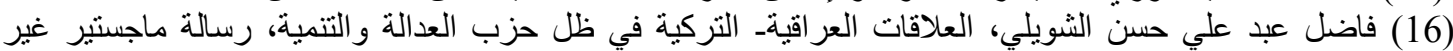

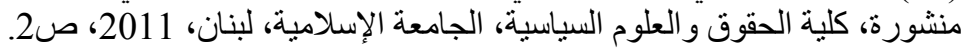
(17) تشارلز تريب، صفحات من تاريخ العراق، ترجمة زينة جابر إدريس، الدار العربية للعلوم، بيروت، 2006، 196 ص (18) وقعت تركيا وباكستان اتفاق دفاع مشترك بينهما على عهد وزارة( فاضل الجمالي) الثانية، عرف بالحلف التركي-

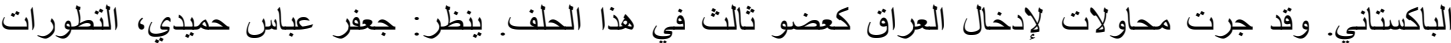

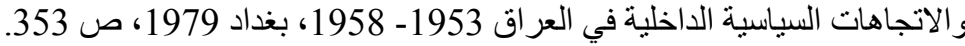

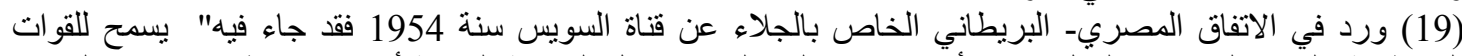

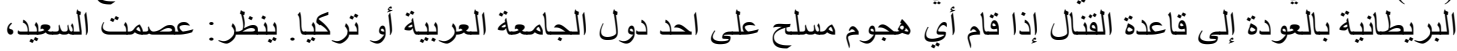

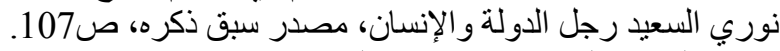

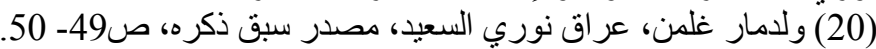

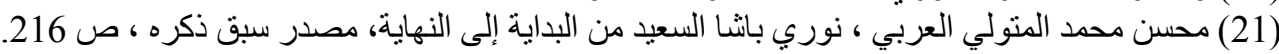

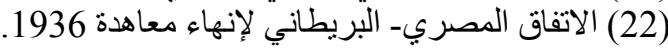

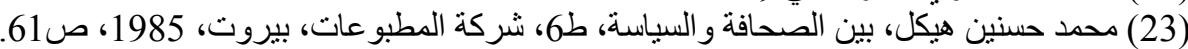

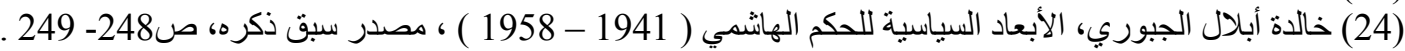

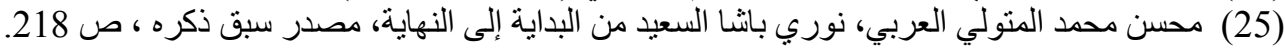

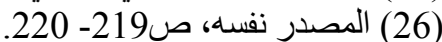

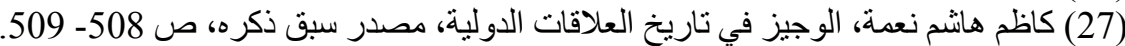

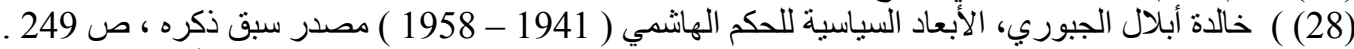

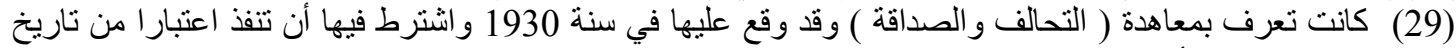

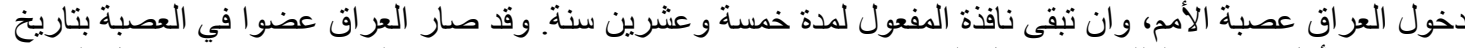

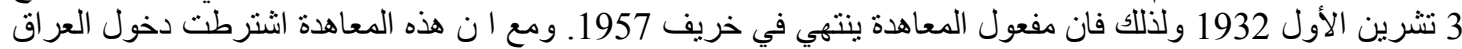
عصبة الأمم، و إنهاء الانتداب البريطاني، فان الر أي العراقي العي العام لم يكن راضي راضيا عنها. 
International Journal of Humanities and Social Sciences

website:www.ijohss.com

Email:editor@ijohss.com

ISSN: $2415-4822$

\section{العدد (15) ل \\ Volume (15) September 2020}

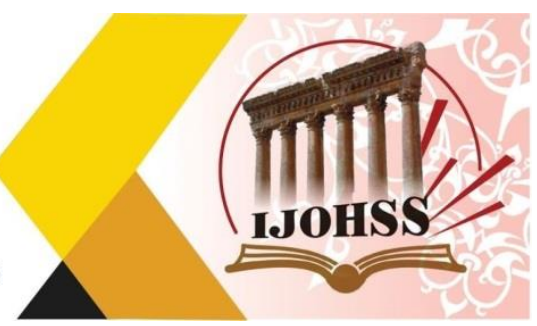

ولدمار غلمن، عراق نوري السعيد، مصدر سبق ذكره، ص 59

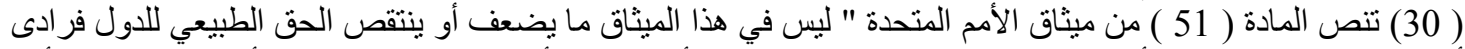

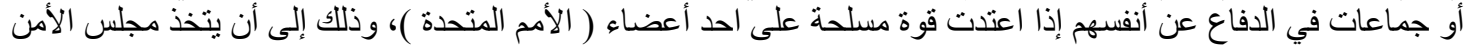

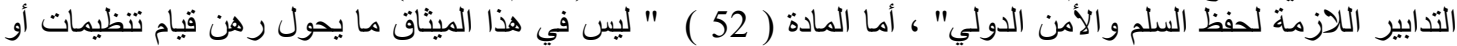

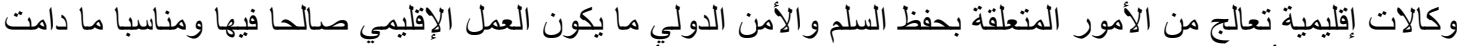

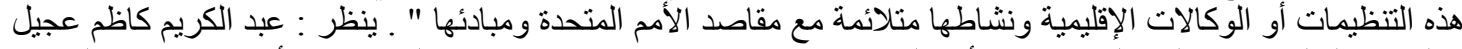

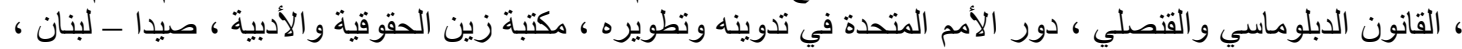

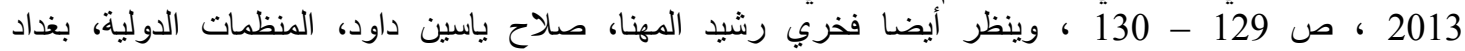

1220صن، 2009،

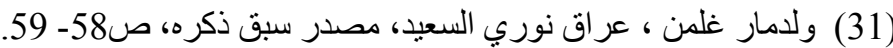

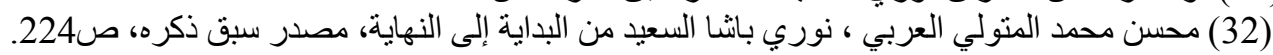

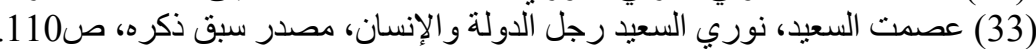

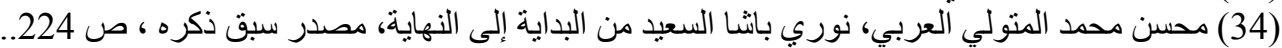

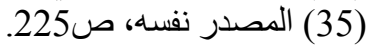

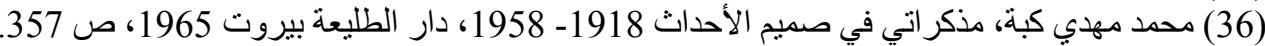

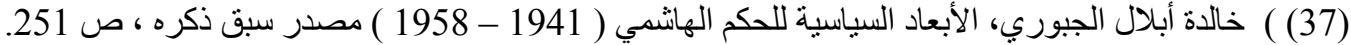

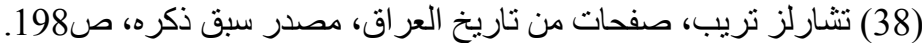

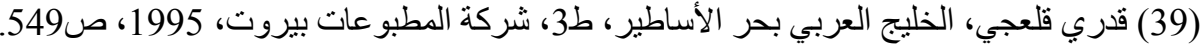

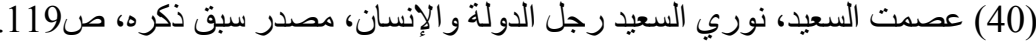

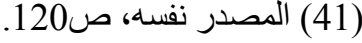

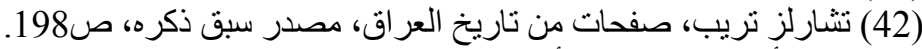

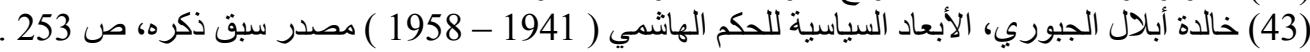

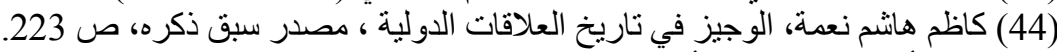

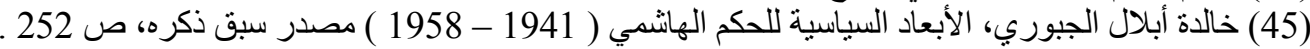

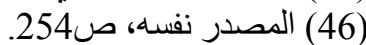

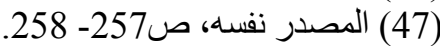

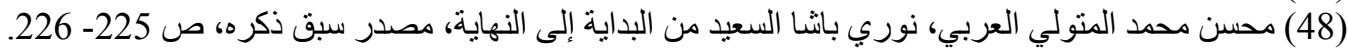

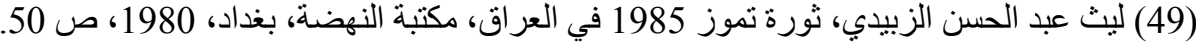

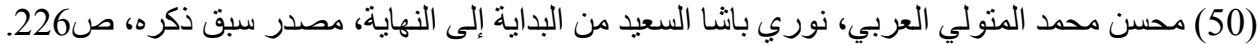

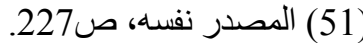

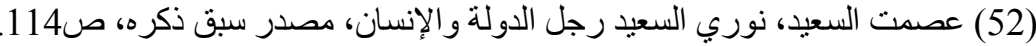

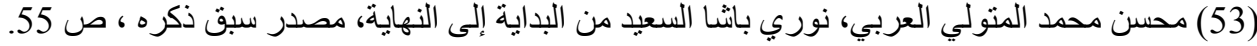

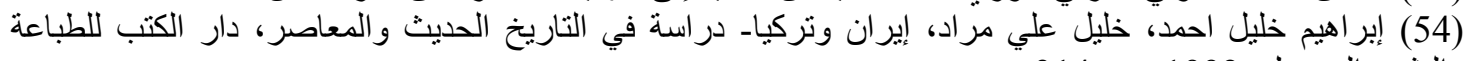

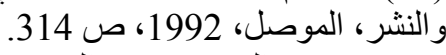

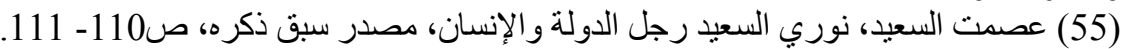

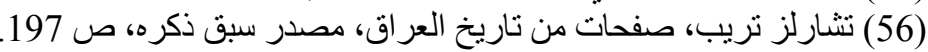

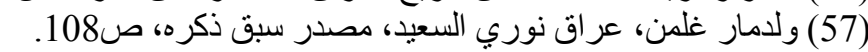

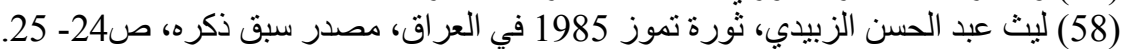

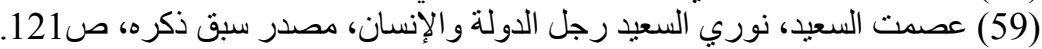

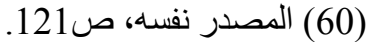

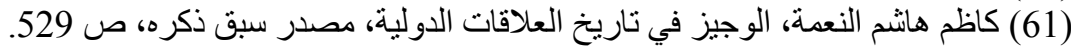

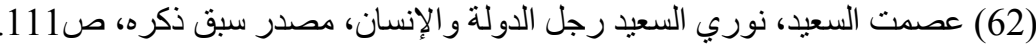

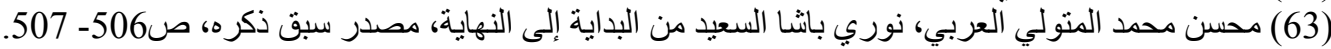

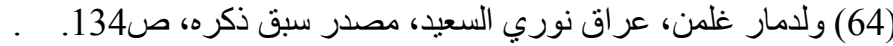

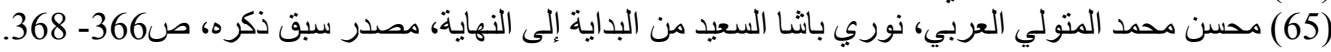

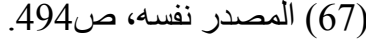




\section{المجلة اللحولية اللفلوم الإنسانية والاجمانماعية}

International Journal of Humanities and Social Sciences website:www.ijohss.com Email:editor@ijohss.com ISSN: $2415-4822$

\section{العدد (15) العبتمبر 2020 Volume (15) September 2020}

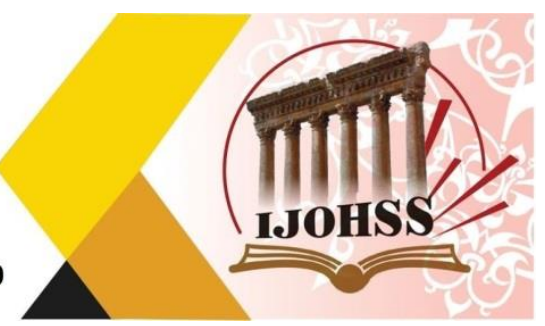

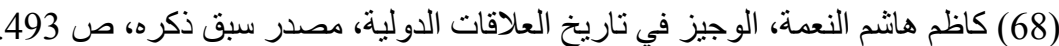

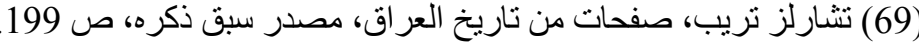

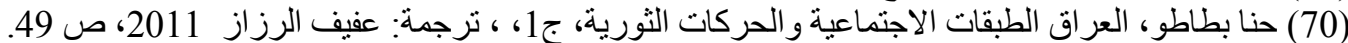

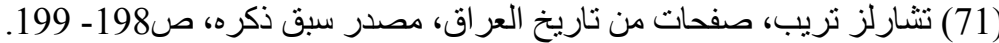
(72) فيبي مار ، تاريخ العراق المعاصر العها الجمهوري الأول، ج1، مؤسسة مرتضى للكتاب العر اقي، مصر، 2009،

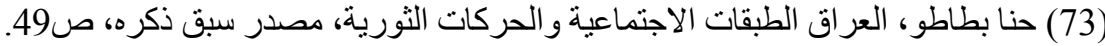

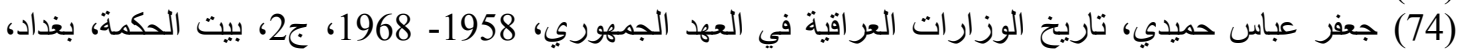
2005 (75) جعفر عباس حميدي، تاريخ الوزارات الترات العراقية في العهد الجمهوري، 1958- 1968، ج2، الجية بيت الحكمة،

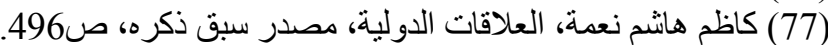

(78) جعفر عباس حميدي، تاريخ الوزارات العراتية اقية في العهد الجمهوري، 1958- 1968، ج2، بيت الحكمة، بغداد،

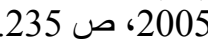

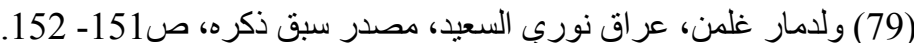
(80) جعر عباس حميدي، تاريخ الوزارات العراقية في العهذ الجمهوري، 1958- 1968، ج2، مصدر سبق ذكره،

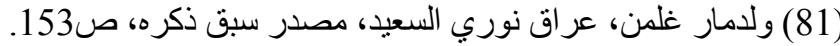

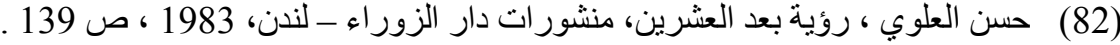

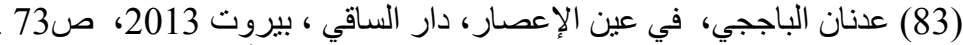

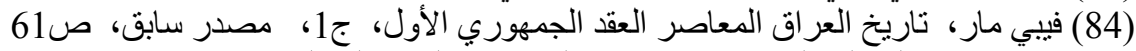

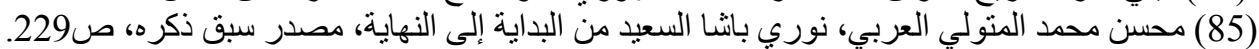

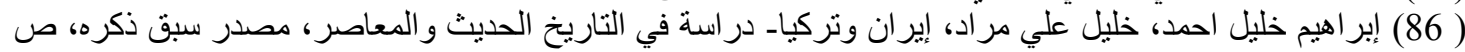

(87) كريم محمد حمزة، دهام محمود علي الجبوري، القوى الفاعلة في المجتمع التركي، بيت الحكمة، بغداد 2002، ص

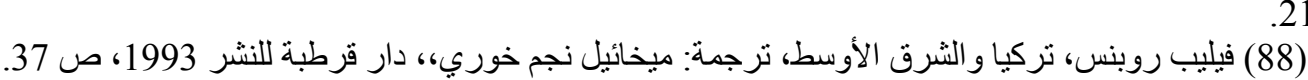

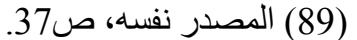

(90) إبر اهيم خليل احمد، خليل علي مر اد، إيران وتركيا- دراسة في التاريخ الحديث و المعاصر، مصدر سبق ذكره، ص

. $192-191$

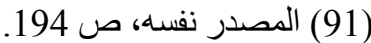

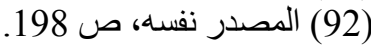

(93) كاظم هاشم نعمة، الوجيز في تاريخ العلاقات، مصدر سبق ذكره، ص 460- 461. 


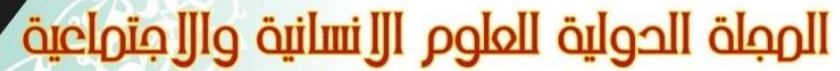
International Journal of Humanities and Social Sciences website:www.ijohss.com Email:editor@ijohss.com ISSN: $2415-4822$
العدد (15) Volume (15) September 2020

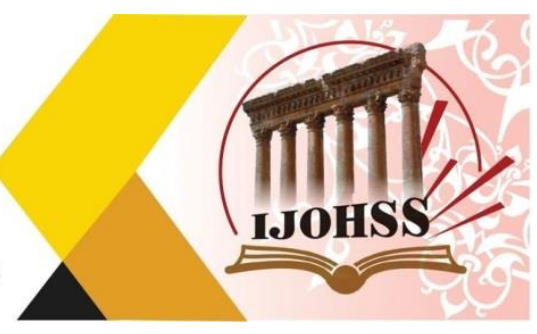

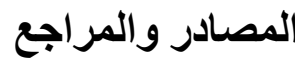

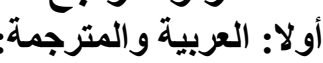

1- إبراء اهيم خليل والمثرجمة، خليل علي مراد، إيران وتركيا- دراسة في التاريخ الحديث والمعاصر، دار الكتب

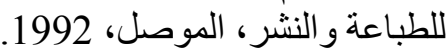

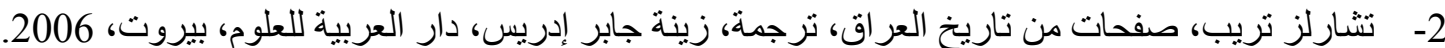

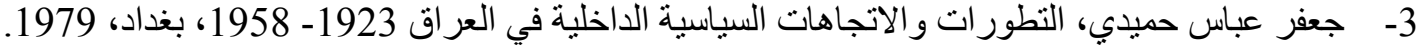

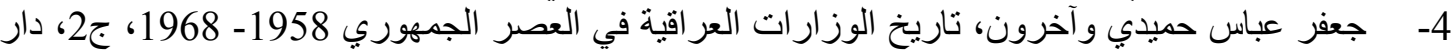

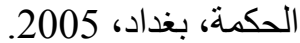
5- حسن العلوي، رؤية بعد العشرين، منشور ات الزوات الزور اء، لندن، 1983.

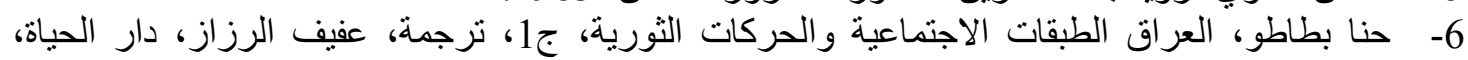

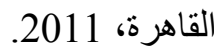
7- الدة أبلال الجبوري، الأبعاد السياسية للحكم الهاثمي 1941- 1958، محاكاة للار اسات و النشر و التوزيع،

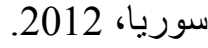

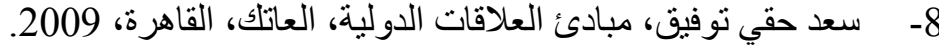

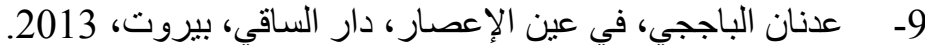

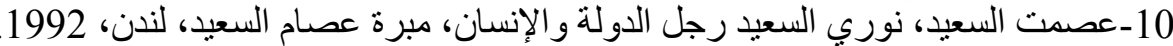
11 - عبد الكريم كاظم عجيل، القانون الدبلوماسي و القنصلي دور الأمم المتحدة في تدوينه وتطويره، منشور النيات

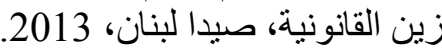
12 - فيبي مار، تاريخ العراق المعاصر في الجمهوري الأول، ج1، مؤسسة مصر مرتضى للكتاب العراقي،

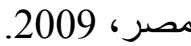

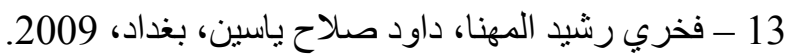

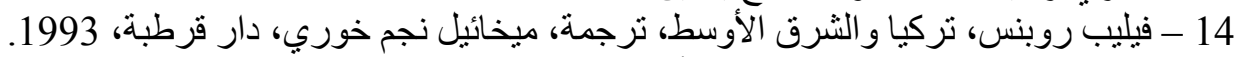

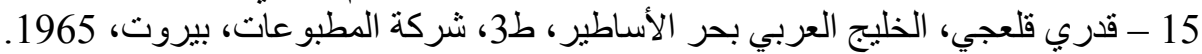
16 - كريم محمد حمزة الجبوري، هشام محمود علي، القوى الفاعلة في المجتمع التركي، بيت التئ الحكمة، بغداد، .2002

17 - كاظم هاثم نعمة، الوجيز في تاريخ العلاقات الدولية، دار الحكمة للطباعة و النشر ، بغداد، 1992. 18 - 18 19 ـ ليث عبد الحسن الزبيدي، ثورة 14 تموز 1958 في العراق، ط2، منشور ات مكتبة اليقظة العربية، بغداد، .1982

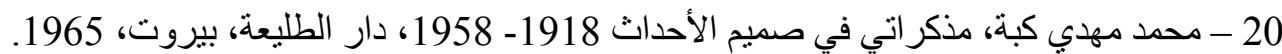
21 - محسن محمد المنولي الّربي، نوري فيكي بانشا السعيد من البداية إلى النهاية، الدار العربية للموسوعات،

بيروت، 2005.

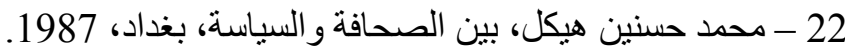
23 - ولدمار غلمن، عراق نوري السعيد ، ( بدون مكان طبع )، 1965.

ثُانيا: الرسائل والأطاريح الجامعية

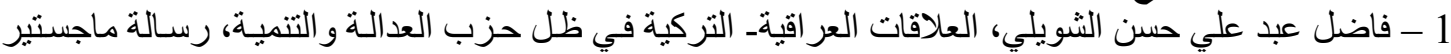
غير منشورة، كلية الحقوق و العلوم السياسية، الجامعة الإسلامية، لبنان، 2011.

ثُالثا: المقابلات الشخصية

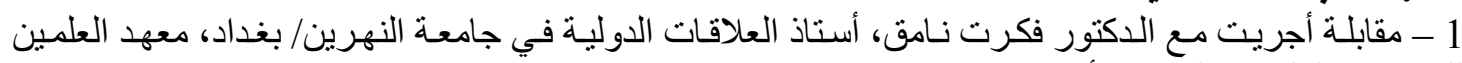
للار اسات العليا في النجف الأشرف، بتاريخ 17 / 12/ 2013. 


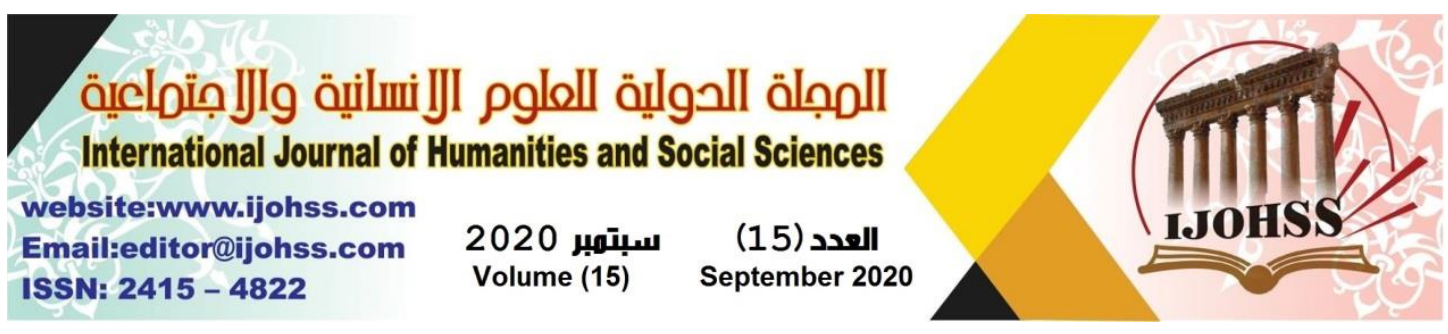

\section{References}

First: Arabic and translated:

1- Ibrahim Khalil Ahmad, Khalil Ali Murad, Iran and Turkey - A study in modern and contemporary history, Dar Al Kutub for Printing and Publishing, Mosul, 1992.

2- Charles Tripp, Pages from the History of Iraq, translation, by Zeina Jaber Idris, Dar Al Arabiya for Sciences, Beirut, 2006.

3- Jaafar Abbas Hamidi, Developments and Domestic Political Trends in Iraq 19231958, Baghdad, 1979.

4- Jaafar Abbas Hamidi and others, History of Iraqi Ministries in the Republican Era 1958-1968, Part 2, Dar Al-Hikma, Baghdad, 2005.

5- Hassan Al-Alawi, A Vision After Twenty, Al-Zawra Publications, London, 1983.

6- Hanna Batatu, Iraq, Social Classes and Revolutionary Movements, Part 1, translation, Afif Al-Razzaz, Dar Al-Hayat, Cairo, 2011.

7- Khalida Abalal Al-Jubouri, The Political Dimensions of the Hashemite Rule 19411958, Simulation of Studies, Publishing and Distribution, Syria, 2012.

8- Saad Hakki Tawfiq, Principles of International Relations, Al-Atak, Cairo, 2009.

9- Adnan Al-Bajji, In Ain Al-Asyar, Dar Al-Saqi, Beirut, 2013.

10- Ismat Al-Saeed, Nuri Al-Saeed, the statesman and man, Issam Al-Saeed Foundation, London, 1992.

11- Abd al-Karim Kazem Ajil, Diplomatic and Consular Law, The Role of the United Nations in Codifying and Development, Zain Legal Publications, Saida Lebanon, 2013.

12- Phoebe Marr, The Contemporary History of Iraq in the First Republic, Part 1, Misr Mortada Foundation for Iraqi Book, Egypt, 2009.

13- Fakhri Rashid Al-Muhanna, Daoud Salah Yassin, Baghdad, 2009.

14- Philip Robins, Turkey and the Middle East, translated by Mikhail Najm Khoury, Cordoba House, 1993.

15- Qadri Qalaji, The Arabian Gulf, the Sea of Legends, 3rd Edition, Publications Company, Beirut, 1965.

16- Karim Muhammad Hamza al-Jubouri, Hisham Mahmoud Ali, Active Forces in Turkish Society, House of Wisdom, Baghdad, 2002.

17- Kazem Hashem Nehme, Al Wajeez in the History of International Relations, House of Wisdom for Printing and Publishing, Baghdad, 1992.

18 -------, International Relations, Iyad Printing Company, Baghdad, 1987.

19- Laith Abdul-Hasan Al-Zubaidi, The Revolution of July 14, 1958 in Iraq, 2nd Edition, Publications of the Arab Awakening Library, Baghdad, 1982.

20- Muhammad Mahdi Kubba, My Diary in the Heart of Events 1918-1958, Dar Al Taleea, Beirut, 1965.

21- Mohsen Muhammad Al-Mitwalli Al-Arabi, Nuri Pasha Al-Saeed from beginning to end, Arab House of Encyclopedias, Beirut, 2005.

22 - Muhammad Hassanein Heikal, Between Journalism and Politics, Baghdad, 1987.

23- Weldmar Gholman, Nuri al-Saeed's Iraq (without a place of printing), 1965. 


\section{المبلة اللحولية اللملوم الآسانية والإمتصاعية International Journal of Humanities and Social Sciences}

website:www.ijohss.com

Email:editor@ijohss.com

ISSN: $2415-4822$

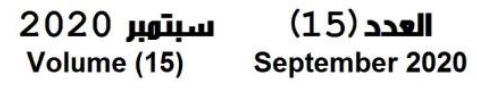

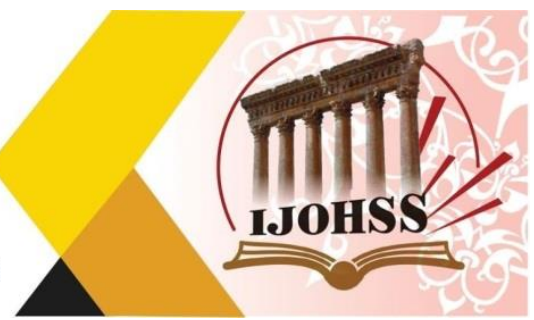

Second: University theses and dissertations

1- Fadil Abd Ali Hassan Al-Shuwaili, Iraqi-Turkish Relations under the Justice and Development Party, an unpublished master's thesis, Faculty of Law and Political Science, Islamic University, Lebanon, 2011.

\section{Third: Personal interviews}

1 - An interview conducted with Dr. Fikret Namiq, Professor of International Relations at Al-Nahrain University / Baghdad, Al-Alamein Institute for Higher Studies in Najaf, on 7/12/2013. 